UCRL-ID-134691

\title{
Experimental Investigations of Material Models for Ti-6Al-4V and 2024-T3
}

Don Lesuer

May 3, 1999

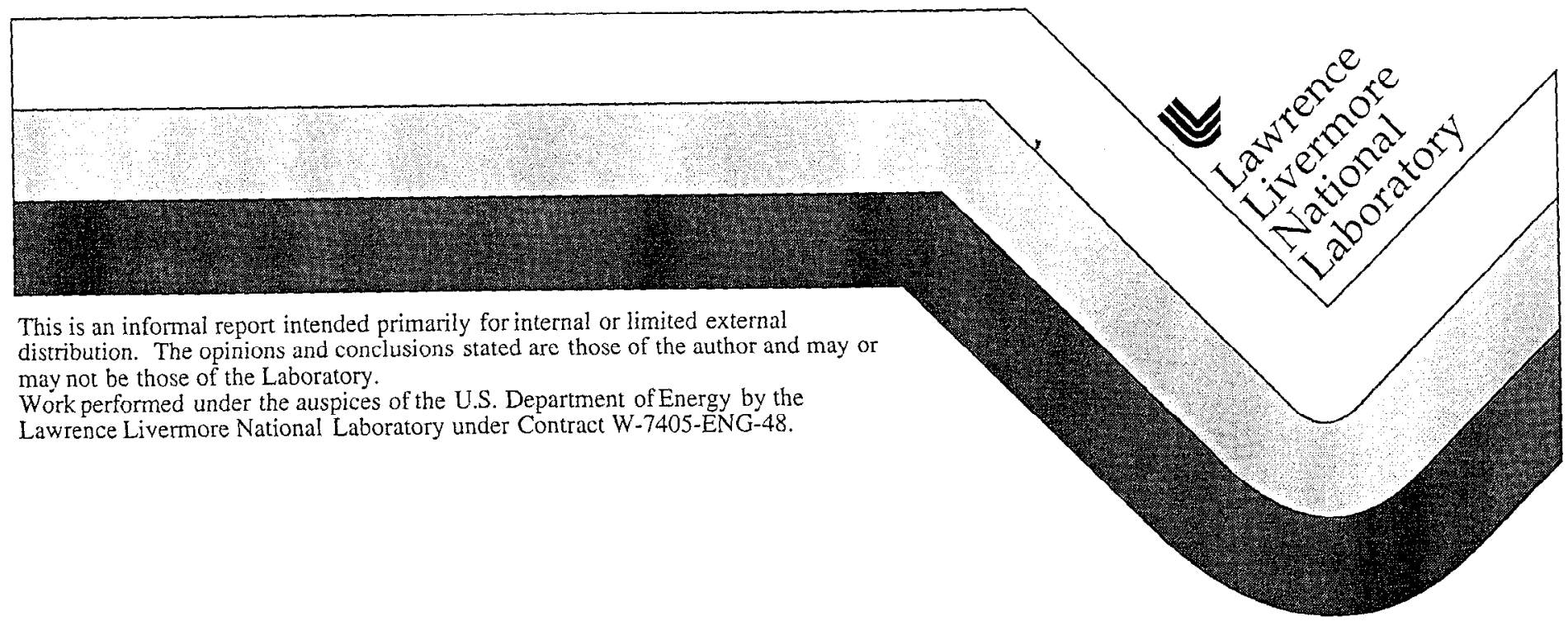




\section{DISCLAIMER}

This document was prepared as an account of work sponsored by an agency of the United States Government. Neither the United States Government nor the University of California nor any of their employees, makes any warranty, express or implied, or assumes any legal liability or responsibility for the accuracy, completeness, or usefulness of any information, apparatus, product, or process disclosed, or represents that its use would not infringe privately owned rights. Reference herein to any specific commercial product, process, or service by trade name, trademark, manufacturer, or otherwise, does not necessarily constitute or imply its endorsement, recommendation, or favoring by the United States Government or the University of California. The views and opinions of authors expressed herein do not necessarily state or reflect those of the United States Government or the University of California, and shall not be used for advertising or product endorsement purposes.

This report has been reproduced directly from the best available copy.

Available to DOE and DOE contractors from the Office of Scientific and Technical Information

P.O. Box 62, Oak Ridge, TN 37831

Prices available from (423) 576-8401

Available to the public from the National Technical Information Service

U.S. Department of Commerce

5285 Port Royal Rd.

Springfield, VA 22161 


\section{Experimental Investigations of Material Models for Ti-6Al-4V and 2024-T3}

May 3, 1999

Final Report 


\section{TABLE OF CONTENTS}

Page

EXECUTIVE SUMMARY

1. INTRODUCTION 1

1.1 Background and Motivation 1

1.2 Johnson-Cook Material Model 1

2. HIGH RATE RESPONSE OF Ti-6Al-4V AND 2024-T3 2

2.1 Material 2

2.2 Experimental Procedures 4

2.3 Data for Ti-6Al-4V 5

2.3.1 Stress-Strain Data 5

2.3.2 Microstructural Characterization $\quad 7$

2.3.3 Data Analysis 9

2.4 Data for 2024-T3 12

2.4.1 Stress-Strain Data $\quad 12$

2.4.2 Microstructural Characterization 13

2.4.3 Data Analysis 13

3. ANALYSIS OF JOHNSON-COOK MATERIAL MODEL 15

4. NEW CONSTANTS FOR JOHNSON-COOK MATERIAL MODEL 16

$4.1 \quad \mathrm{Ti}-6 \mathrm{Al}-4 \mathrm{~V} 216$

$\begin{array}{lll}4.2 & 2024-\mathrm{T} 3 & 16\end{array}$

5. SUMMARY 22

6. ACKNOWLEDGMENTS 23

7. REFERENCES 23

APPENDIX ' ' 26

A --- Procedures for Obtaining Parameters for Johnson-Cook Material Model 26 


\section{LIST OF FIGURES}

Figure

Page

$1 \quad$ Microstructure of Ti-6Al-4V Alloy. $\quad 3$

2 Microstructure of 2024-T3 Alloy. 4

3 Stress-Strain Response for Ti-6Al-4V Tested in Compression at a Strain Rate 5 of $4500 \mathrm{~s}^{-1}$.

4 Stress-Strain Response for Ti-6Al-4V Tested in Tension at a Strain Rate of $5200 \mathrm{~s}^{-1}$.

5 Photograph of Ti-6Al-4V Sample After Testing in Compression.

6 Fracture Surface of Ti-6Al-4V Sample Tested in Compression. 7

7 Shear Band in Ti-6Al-4V Sample After Testing in Compression. 8

8 Cross-section of Ti-6Al-4V Sample After Testing in Tension. 8

$9 \quad$ Fracture Surface of Ti-6Al-4V Sample Tested in Tension. 9

10 Comparison of the High-Strain-Rate, Stress-Strain Response of the Ti-6Al-4V 9

Alloy in Tension and Compression. Data is also Provided for other High-Rate

Studies of Annealed Ti-6Al-4V from the Literature. The Predictions of the Johnson-Cook Material Model Using the Original Parameters are Shown in the Figure.

11 Comparison of the Stress-Strain Rate Response of Ti-6Al-4V Obtained from the this study as well as other Studies from the Literature. All Data Was Obtained at a Strain of .04 with the Exception of the Study by Wulf, which was Obtained at a Strain of .1. The Predictions of the Johnson-Cook Material Model Using the Original Parameters are also Shown in the Figure.

12 Stress-Strain Response for 2024-T3 Tested in Compression at a Strain Rate of $4000 \mathrm{~s}^{-1}$.

13 Stress-Strain Response for 2024-T3 Tested in Tension at a Strain Rate of $8000 \mathrm{~s}^{-1}$.

14 Comparison of the High-Strain-Rate, Stress-Strain Response of 2024-T3 in

Tension and Compression.

15 Stress-Strain Rate Data Obtained by Johnson for the Ti-6Al-4V Alloy at a Plastic

Strain of.002. The Predictions of the Johnson-Cook Model Using the Original

Parameters are also Shown in the Figure.

16. Comparison of the High-Strain-Rate, Stress-Strain Response of the Ti-6Al-4V

Alloy Predicted by the Johnson-Cook Material Model (Using the New

Material Parameters) with Experimental Data in Tension and Compression. 
17. Comparison of the Low-Strain-Rate $\left(.0001 \mathrm{~s}^{-1}\right)$, Stress-Strain Response of the Ti-6Al-4V Alloy as Predicted by the Johnson-Cook Material Model (using the New Material Parameters) with Experimental Data in Tension.

18. Comparison of the Stress-Strain Rate Response of the Ti-6Al-4V Alloy as predicted by the Johnson-Cook Material Model (Using the New Material Parameters) with Experimental Data. Calculations and Data were taken at a Strain of .04.

19. Comparison of the Stress-Temperature Response of the Ti-6Al-4V Alloy as predicted by the Johnson-Cook Material Model (using the New Material Parameters) with Experimental Data.

20. Predicted Adiabatic Stress-Strain Response for the Ti-6Al-4V Alloy in Tension, Shear and Compression at a Strain Rate of $5000 \mathrm{~s}^{-1}$. The Predicted Failure Strains and Resulting Temperature Rise in the Sample are Shown in the Figure.

21. Comparison of the High-Strain-Rate, Stress-Strain Response of the 2024-T3 Alloy Predicted by the Johnson-Cook Material Model (Using the New Material Parameters) with Experimental Data in Tension and Compression.

22 Comparison of the Low-Strain-Rate $\left(.0005 \mathrm{~s}^{-1}\right)$, Stress-Strain Response of the 2024-T3 Alloy as Predicted by the Johnson-Cook Material Model (using the New Material Parameters) with Experimental Data in Tension.

23 Comparison of the Stress-Strain Rate Response of the 2024-T3 Alloy as predicted by the Johnson-Cook Material Model (Using the New Material Parameters) with Experimental Data. Calculations and Data were taken at a Strain of .1.

24 Comparison of the Stress-Temperature Response of the 2024-T3 Alloy as predicted by the Johnson-Cook Material Model (using the New Material Parameters) with Experimental Data. Calculations and Data were taken at a Strain Rate of $.0005 \mathrm{~s}^{-1}$ and a strain of .002 .

25 Predicted Adiabatic Stress-Strain Response for the 2024-T3 Alloy in Tension, Shear and Compression at a Strain Rate of $6000 \mathrm{~s}^{-1}$. The Predicted Failure Strains and Resulting Temperature Rise in the Sample are Shown in the Figure.

A1 $\sigma-\sigma_{0}$ versus Plastic Strain for the Ti-6Al-4V Alloy at a Strain Rate of $5000 \mathrm{~s}^{-1}$. $\sigma_{0}$ is the Stress at 0 Plastic Strain.

A2 $\sigma / \sigma_{1}$ versus Strain Rate for the Ti-6Al-4V Alloy. $\sigma_{1}$ is the stress at a strain rate of $1 \mathrm{~s}^{-1}$.

A3 Stress versus Temperature for the Ti-6Al-4V Alloy at Both High Strain Rates and Low Strain Rates.

A4 $\sigma / \sigma_{\mathrm{a}}$ versus $\mathrm{T}^{*}$ for the Ti-6Al-4V Alloy. $\sigma_{\mathrm{a}}$ is the stress at $298 \mathrm{~K}$ and ' $\mathrm{I}^{*}$ is defined in the text. 


\section{LIST OF TABLES}

Table

Page

1 Chemical Composition of 2024-T3 Alloy

2 Manufacturer Supplied Static Properties for 2024-T3 4

3

3 Fracture strains for Ti-6Al-4V and 2024-T3

6

High Rate Literature Data for Annealed Ti-6Al-4V

10

Instability Strains for 2024-T351 in Compression

15

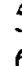

Original Parameters for Johnson-Cook Material Model

16

7 Physical Properties of Ti-6Al-4V and 2024-T3

16

8 New Parameters for Johnson-Cook Material Model 


\section{EXECUTIVE SUMMARY}

This report describes studies of the deformation and failure behavior of Ti-6Al-4V and 2024-T3 aluminum. Data was obtained at high strain rates and large strains using the split Hopkinson pressure bar technique. This information, plus additional data from the literature, was used to critically evaluate the ability of the Johnson Cook material model to represent the deformation and failure response of Ti-6Al-4V and 2024-T3 under conditions relevant to simulations of engine containment and the influence of uncontained engine debris on aircraft structures. This model is being used in the DYNA3D finite element code, which is being developed/validated for evaluating aircraft/engine designs relative to the federal airworthiness standards and for improving mitigation/containment technology. The results of the experimental work reported here were used to define a new set of material constants for the strength component of the Johnson Cook model for Ti-6Al-4V and 2024-T3. The capabilities and limitations of the model are reviewed. The model can accurately represent the stress-strain response of the materials. The major concern with the Johnson Cook material model is its ability to accurately represent the stress - strain rate response at strain rates greater than $10^{3}-10^{4} \mathrm{~s}^{-1}$. Additional work is also needed to adequately account for failure via shear localization, which was the dominant failure mode at high strain rates in both materials. Failure modeling in both Ti-6Al-4V and 2024-T3 will be considered further in future reports. 


\section{INTRODUCTION.}

\subsection{BACKGROUND AND MOTIVATION.}

The Program Plan for the FAA Aircraft Catastrophic Failure Prevention Program has established a framework for research and development that will produce standard tools for evaluating aircraft/engine designs relative to the federal airworthiness standards and for improving mitigation/containment technology. A key tool being developed and validated under this program is a finite element code capable of accurate simulations involving engine containment and the influence of uncontained engine debris on aircraft structures. A critical component of the code is a validated material model(s) that can adequately represent the penetration and perforation of the aircraft/engine materials. Material models which can adequately represent the deformation response during high rate loading must account for large strains (and the resulting strain hardening or softening), as well as large changes in strain rate and temperature. Several models have been developed which can represent, to varying degrees, the high rate deformation response of materials. Examples include models by Johnson-Cook (JC) [1-3], Zerilli-Armstrong [4-6], Steinberg-Guinan [7] and Follansbee-Kocks (mechanical threshold stress model) [8]. Of these models the JC model is the most widely used and has been introduced into the DYNA3D code. The JC model was developed during the 1980's to study impact, ballistic penetration and explosive detonation problems. The model has proven to be very popular and has been used extensively by a number of national laboratories, military laboratories and private industry to study high rate, large strain problems. In addition, the participants in this program (including Allied Signal Engines, Boeing Commercial Aircraft Corporation, Lawrence Livermore National Laboratory and United Technologies, Pratt \& Whitney) are using the JC model and the DYN $\Lambda 3 \mathrm{D}$ code for simulations of containment and the mitigation of uncontained engine debris. The JC material model has both a strength [1, 2,9] and a damage component [3] to the model. The damage component has a cumulative damage law which can be used to assess failure.

In this report, we describe studies of the deformation and failure behavior of Ti-6Al-4V and 2024T3 aluminum. Data was obtained at high strain rates and large strains using the split Hopkinson pressure bar technique. This information, plus additional data from the literature, was used to critically evaluate the ability of the JC model to represent the deformation and failure response of these materials under conditions relevant to simulations of engine containment and the influence of uncontained engine debris on aircraft structures. The results were used to define a new set of material constants for the strength component of the JC model for Ti-6Al-4V and 2024-T3. The failure modeling of these materials will be revisited in a future report.

\subsection{JOHNSON-COOK MATERIAL MODEL.}

The formulation for the JC model is empirically based and represents the flow stress with an equation of the form,

$$
\sigma=\left[\mathrm{A}+\mathrm{B} \varepsilon^{\mathrm{n}}\right]\left[1+\mathrm{Cln} \dot{\varepsilon}^{*}\right]\left[1-\mathrm{T}^{* \mathrm{~m}}\right]
$$

where $\sigma$ is the effective stress, $\varepsilon$ is the effective plastic strain, $\dot{\varepsilon}^{*}$ is the normalized effective plastic strain rate (typically normalized to a strain rate of $1.0 \mathrm{~s}^{-1}$ ), $\mathrm{n}$ is the work hardening exponent and $\mathrm{A}$, $\mathrm{B}, \mathrm{C}$ and $\mathrm{m}$ are constants. The quantity $\mathrm{T}^{*}$ is defined as

$$
\mathrm{T}^{*}=(\mathrm{T}-298) /\left(\mathrm{T}_{\text {melt }}-298\right)
$$


where $T_{\text {melt }}$ is the melting temperature and is typically taken as the solidus temperature for an alloy. The strength of the material is thus a function of strain, strain rate and temperature. The model assumes that the strength is isotropic and independent of mean stress.

The values of $\mathrm{A}, \mathrm{B}, \mathrm{C}, \mathrm{n}$ and $\mathrm{m}$ are determined from an empirical fit of flow stress data (as a function of strain, strain rate and temperature) to Equation (1). For high rate deformation problems, we can assume that an arbitrary percentage of the plastic work done during deformation produces heat in the deforming material. For many materials, $90-100 \%$ of the plastic work is dissipated as heat in the material. Thus the temperature used in Equation (1) can be derived from the increase in temperature according to the following expression

$$
\Delta \mathrm{T}=\frac{\alpha}{\rho \mathrm{c}} \int \sigma(\varepsilon) \mathrm{d} \varepsilon
$$

where $\Delta \mathrm{T}$ is the temperature increase, $\alpha$ is the percentage of plastic work transformed to heat, $\mathrm{c}$ is the heat capacity and $\rho$ is the density.

Fracture in the JC material model is derived from the following cumulative damage law

$$
\mathrm{D}=\Sigma \frac{\Delta \varepsilon}{\varepsilon_{\mathrm{f}}}
$$

in which

$$
\varepsilon_{f}=\left[D_{1}+D_{2} \exp \left(D_{3} \sigma^{*}\right)\right]\left[1+D_{4} \ln \dot{\varepsilon}^{*}\right]\left[1+D_{5} T^{*}\right]
$$

where $\Delta \varepsilon$ is the increment of effective plastic strain during an increment in loading and $\sigma^{*}$ is the mean stress normalized by the cffective stress. The parameters $\mathrm{D}_{1}, \mathrm{D}_{2}, \mathrm{D}_{3}, \mathrm{D}_{4}$ and $\mathrm{D}_{5}$ are constants. Failure is assumed to occur when $D=1$. The current failure strain in the problem $\left(\varepsilon_{\mathrm{f}}\right)$, and thus the accumulation of damage, is a function of mean stress, strain rate and temperature.

2. HIGH RATE RESPONSE OF Ti-6Al-4V AND 2024-T3.

\section{$2.1 \quad$ MATERIAL.}

The Ti-6Al-4V alloy evaluated in this study was obtained from RMI in the form of a hot rolled and annealed plate. The annealing heat treatment was done at $790^{\circ} \mathrm{C}$ for one hour followed by furnace cooling. Before testing, samples were annealed at $730^{\circ} \mathrm{C}$ for one hour and air cooled. The alloy was processed to conform with specification AMS 4911, which is typically used for procurement of Ti-6Al-4V for aircraft containment structures. This specification was also used for procurement of Ti-6Al-4V plate for ballistic testing in this program including sub-scale tests by LLNL $(12.7 \mathrm{~mm}$ thick plate) and, full-scale tests by Pratt and Whitney (19.1 mm thick plate). The microstructurc of the as-tested material is shown in Fig. 1 and the orientations of the $0^{\circ}, 90^{\circ}$ and normal (n, through thickness) directions are indicated in the figure. The microstructure consists of roughly equiaxed alpha and transformed beta phase, which is a typical microstructure for the Ti-6Al-4V alloy manufactured to the AMS 4911 specification. Compression Hopkinson bar samples were machined with the compression axis parallel to the three orthogonal directions shown in Fig. 1. 
Tensile Hopkinson bar samples were prepared with the tensile axis parallel to the two in-plane directions $\left(0^{\circ}\right.$ and $\left.90^{\circ}\right)$ shown in Fig. 1 .

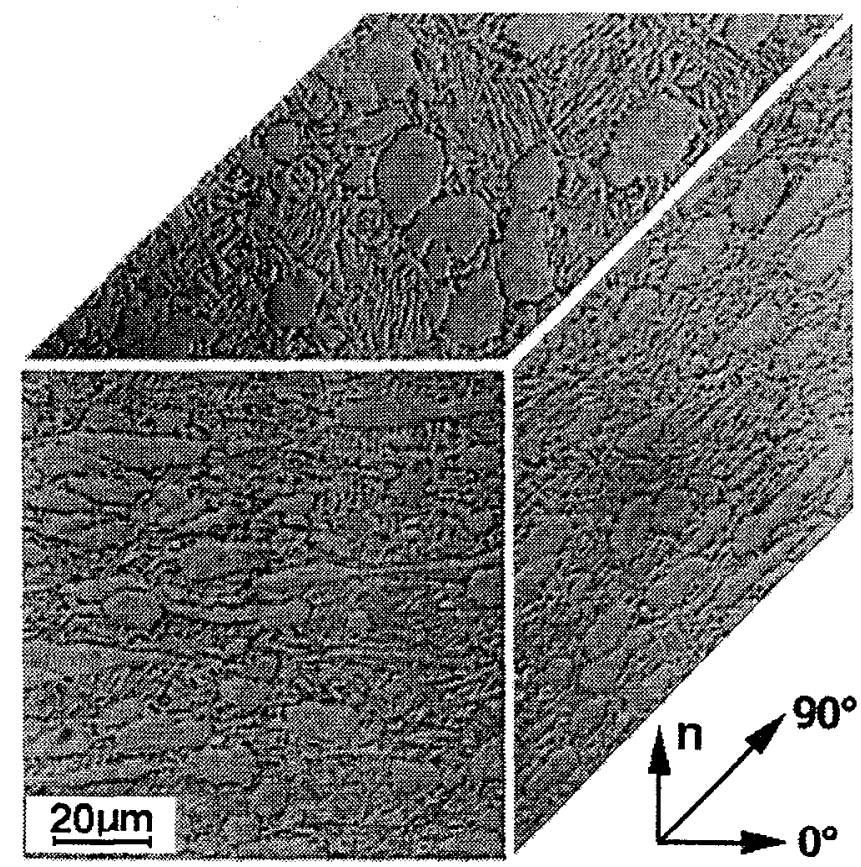

\section{FIGURE 1. MICROSTRUCTURE OF Ti-6Al-4V ALLOY.}

The 2024-T3 alloy evaluated in this study was obtained from Kaiser Aluminum - Trentwood, WA Plant in the form of a $4 \mathrm{~mm}$ thick plate. The material was manufactured to specifications AMS 4037 (revision M) and ASTM-B-209 (revision 96). The chemical composition and mechanical properties of the tested alloy, as supplied by Kaiser, are provided in Tables 1 and 2, respectively. The chemical composition and mechanical properties conform to the requirements of the specifications. The microstructure of the as-tested material is shown in Fig. 2 and the orientations of the $0^{\circ}$ (rolling direction), $90^{\circ}$ and normal (n, through thickness) directions are indicated in the figure. The microstructure consists of highly flattened grains with an aspect ratio of about 3 to 1 in the plane of the sheet. Compression Hopkinson bar samples were machined with the compression axis parallel to the three orthogonal directions shown in Fig. 2. Tensile Hopkinson bar samples were prepared with the tensile axis parallel to the two in-plane directions $\left(0^{\circ}\right.$ and $\left.90^{\circ}\right)$ shown in Fig. 2.

TABLE 1. CHEMICAL COMPOSITION OF 2024-T3

\begin{tabular}{|c|c|}
\hline Aluminum & Balance \\
\hline Copper & $4.76 \%$ \\
\hline Magnesium & $1.38 \%$ \\
\hline Manganese & $0.65 \%$ \\
\hline Iron & $0.22 \%$ \\
\hline Silicon & $0.08 \%$ \\
\hline Zinc & 0.07 \\
\hline Titanium & 0.03 \\
\hline Chromium & 0.01 \\
\hline
\end{tabular}


TABLE 2. MANUFACTURER SUPPLIED STATIC PROPERTIES FOR 2024-T3

\begin{tabular}{|c|c|c|c|c|c|}
\hline \multicolumn{2}{|c|}{ Yield strength (MPa) } & \multicolumn{2}{|c|}{ Ultimate tensile strength (MPa) } & \multicolumn{2}{c|}{ Elongation (\%) } \\
\hline minimum & maximum & minimum & maximum & minimum & maximum \\
\hline 327 & 330 & 474 & 477 & 16.0 & 18.2 \\
\hline
\end{tabular}

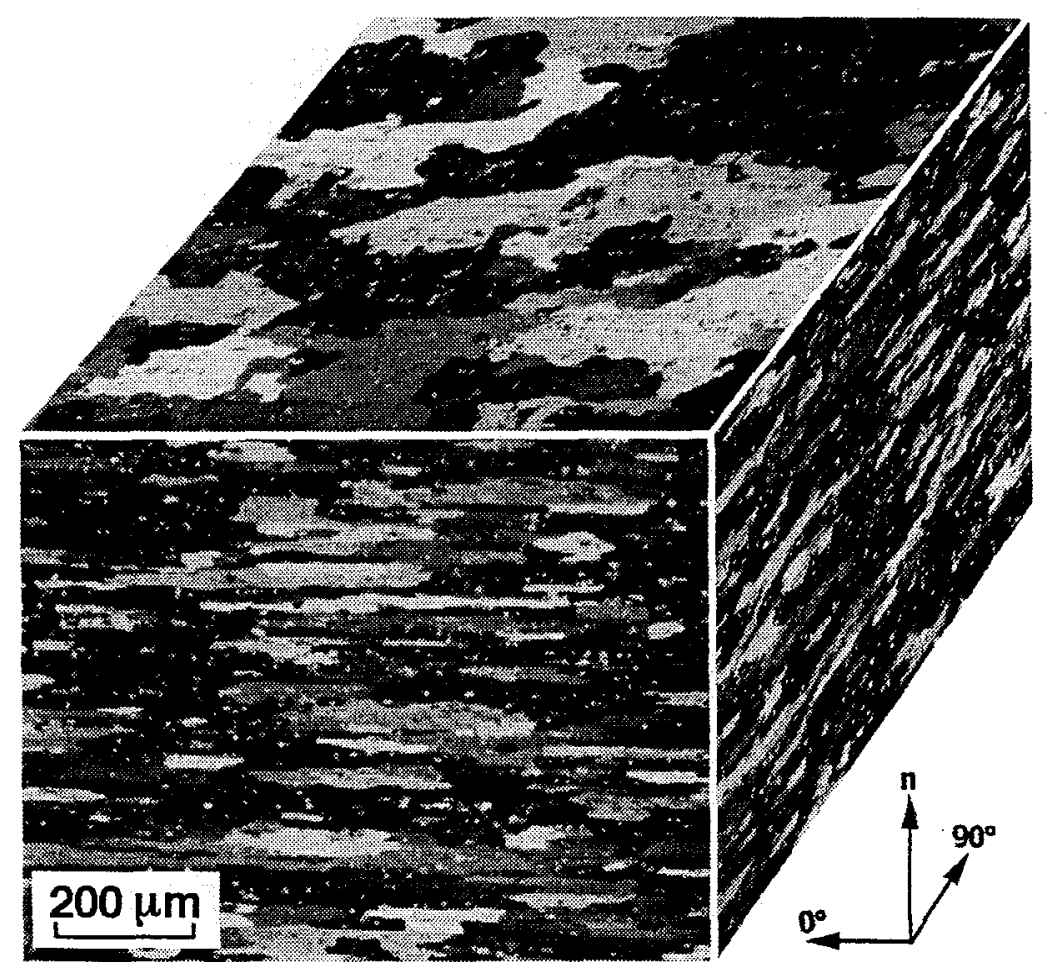

FIGURE 2. MICROSTRUCTURE OF 2024-T3 ALLOY.

\subsection{EXPERIMENTAL PROCEDURES.}

High rate testing was done in both compression and tension using the split Hopkinson pressure bar technique and data was obtained at strain rates of $10^{3}-10^{4} \mathrm{~s}^{-1}$. The compression samples were right circular cylinders with the diameter equal to the height. The compression surfaces were polished flat prior to testing and no lubrication was used. Examination of the samples after testing showed that no barreling occurred. For the Ti-6Al-4V tests, the compression sample diameter was $5 \mathrm{~mm}$ and, for the 2024-T3 tests, the compression sample diameter was $4 \mathrm{~mm}$. The tension samples were flat ( $1 \mathrm{~mm}$ thick) with a gage length of $5 \mathrm{~mm}$ and gage width of $2.5 \mathrm{~mm}$.

In the compression tests, the strain histories for the incident and transmitted waves in the elastic pressure bars were measured and analyzed to determine the nominal stress - strain - strain rate response of the samples. In the tension tests, the strain histories in the elastic pressure bars were used to obtain the stress-time response of the sample. The strain and strain rate behavior of the sample was obtained from high speed photographic images derived from a framing camera. 


\subsection{DATA FOR Ti-6Al-4V.}

\subsubsection{Stress-Strain Data.}

\subsubsection{Compression}

The true stress-true strain response for the Ti-6Al-4V alloy in compression is shown in Fig. 3. The nominal strain rate in these tests was $4500 \mathrm{~s}^{-1}$. Two tests are shown for each of the three testing orientations evaluated. (Stress and strain in compression are negative; however, for the ease of comparison with other data, all stress and strain data reported here are plotted using their absolute values). The repeatability of the test data is excellent. Samples tested in the normal and in -plane $0^{\circ}$ orientations produced stress-strain curves that are virtually identical. Samples tested in the $90^{\circ}$ orientation produced stress-strain curves that are about $250 \mathrm{MPa}$ higher than the curves in the other two orientations. This difference arises because of the texture present in the hot rolled plate. Conrad et al. [10] have shown that hot rolled Ti can develop a texture with the $\langle 11 \overline{2} 0\rangle$ direction nearly parallel to the rolling direction. Textures in hot rolled Ti-6Al-4V are well known for promoting anisotropic flow behavior at quasi-static strain rates. In fact for Ti-6 Al-4V, the tensile properties can vary by $200 \mathrm{MPa}$ with direction in the sheet [11]. The oscillations in the stressstrain curves are the result of gathering data from the long elastic pressure bars. The stress-strain response of the sample is considerably more uniform and can be taken as the average curve through the data in Fig. 3. The fracture strains for the Ti-6Al-4V alloy tested in compression are shown in Table 3 . Fracture in the samples was assumed to occur at the point of pronounced softening.

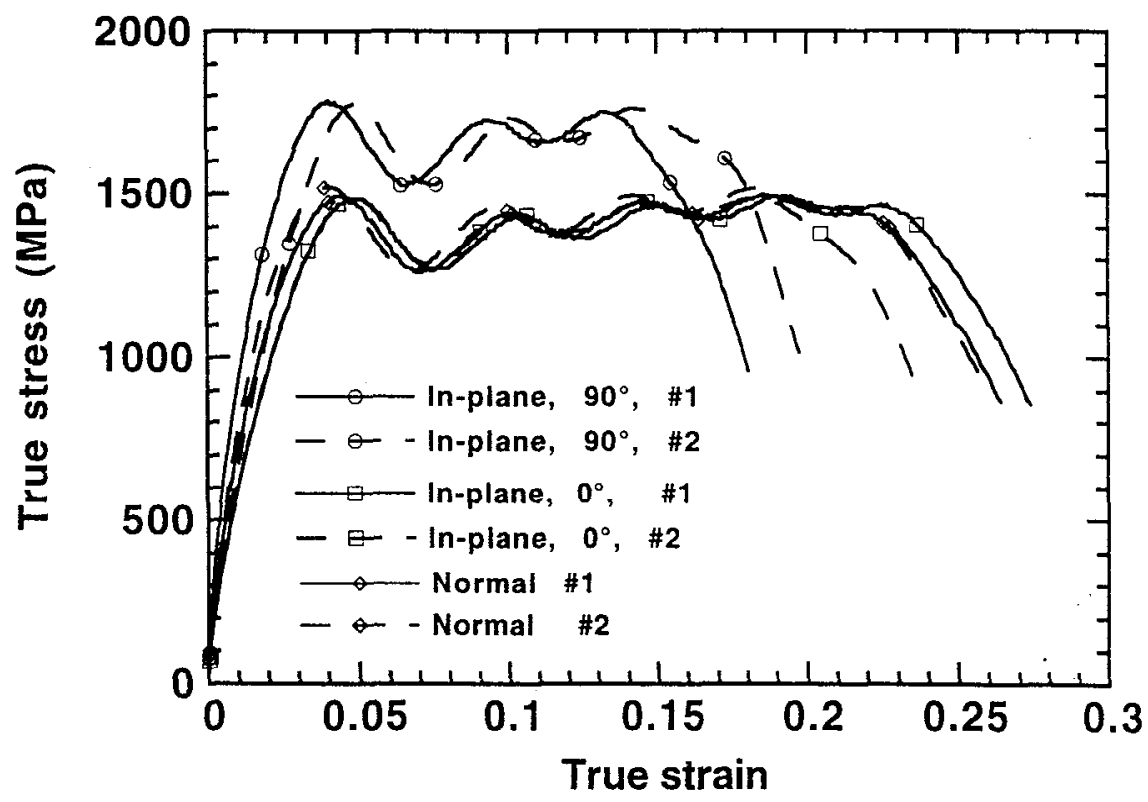

FIGURE 3. STRESS-STRAIN RESPONSE FOR Ti-6Al-4V TESTED INCOMPRESSION AT A STRAIN RATE OF $4500 \mathrm{~s}^{-1}$. 
TABLE 3. FRACTURE STRAINS FOR Ti-6Al-4V and 2024-T3

\begin{tabular}{|c|c|c|c|c|}
\hline & \multicolumn{2}{|c|}{ Ti-6Al-4V } & \multicolumn{2}{c|}{$2024-$ T3 } \\
\hline & Strain rate $\left(\mathrm{s}^{-1}\right)$ & Fracture strain & Strain rate $\left(\mathrm{s}^{-1}\right)$ & Fracture strain \\
\hline $0^{\circ}$ Compression \#1 & 4500 & .19 & 4000 & $>.54$ \\
\hline $0^{\circ}$ Compression \#2 & 4500 & .23 & 4000 & $>.72$ \\
\hline $90^{\circ}$ Compression \#1 & 4500 & .14 & 4000 & $>.54$ \\
\hline $90^{\circ}$ Compression \#2 & 4500 & .18 & 4000 & $>.64$ \\
\hline Normal Compression \#1 & 4500 & .23 & 4000 & $>.54$ \\
\hline Normal Compression \#2 & 4500 & .22 & 4000 & $>.54$ \\
\hline $0^{\circ}$ Tension & 5200 & .22 & 8000 & .29 \\
\hline $90^{\circ}$ Tension & 5200 & .22 & 8000 & .28 \\
\hline
\end{tabular}

\subsubsection{Tension}

The true stress-true strain response for the Ti-6Al-4V alloy in tension is shown in Fig. 4. The nominal strain rate in these tests was $5200 \mathrm{~s}^{-1}$. Test results are shown for both in-plane orientations. In contrast to the data in compression, the data in tension shows that the stress-strain response in the plane is isotropic despite the obvious texture present in the plate as revealed by the anisotropic results in compression. Analysis of Figs. 3 and 4 shows that, with the exception of the compression tests in the $90^{\circ}$ orientation, the stress-strain response is isotropic and independent of testing orientation (tension vs. compression). This point will be discussed further in Section 2.3.3. Data for elastic loading of the sample (in both tension and compression) can not be obtained in these tests due to wave propagation effects. The stress-strain curves shown in Fig. 3 and 4 can be considered valid once the samples have yielded plastically. Once significant plastic strains are developed, stress and strain rate uniformity are achieved in the sample. The framing camera records were used to establish the strain and location in the tensile samples at which fracture initiated. These fracture strains are indicated in Table 3. Fracture of the tensile samples was first observed at the edges of the samples. For both Ti-6Al-4V tensile samples studied, fracture initiated at maximum stress as shown on the stress-strain curves in Fig. 4.

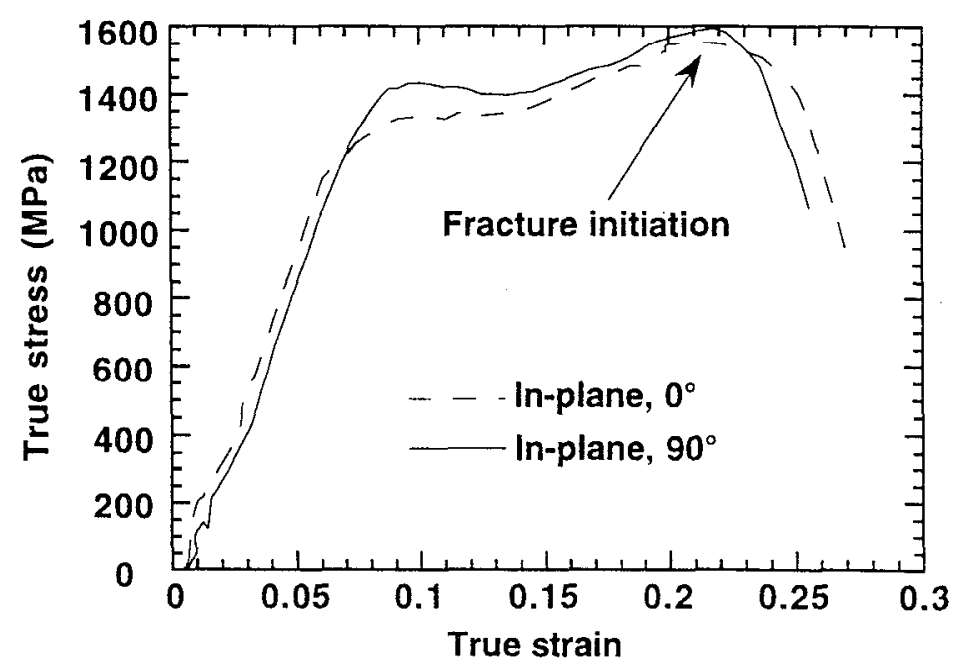

FIGURE 4. STRESS-STRAIN RESPONSE FOR Ti-6Al-4V TESTED IN TENSION AT A STRAIN RATE OF $5200 \mathrm{~s}^{-1}$. 


\subsubsection{Microstructural Characterization.}

Both tension and compression samples were characterized after fracture using optical metallography and scanning electron microscopy. A typical compression sample after testing is shown in Fig. 5. This sample, which was tested with the compression axis parallel to the normal direction in the plate, failed along a shear plane which is oriented at $45^{\circ}$ to the axis of loading. The sample shows very uniform deformation with no indications of barreling. All compression samples of the Ti-6Al-4V alloy, irrespective of orientation, failed along a shear plane similar to Fig. 5. The fracture surface of this sample, which is shown in Fig. 6, exhibits very shallow voids that are approximately $5 \mu \mathrm{m}$ in diameter and experienced growth and interlinkage due to shear deformation. Figure 7 shows a typical adiabatic shear band observed in the compression samples. The width of the shear band is approximately $15 \mu \mathrm{m}$. All compression samples tested, irrespective of orientation, failed due to adiabatic shear localization.

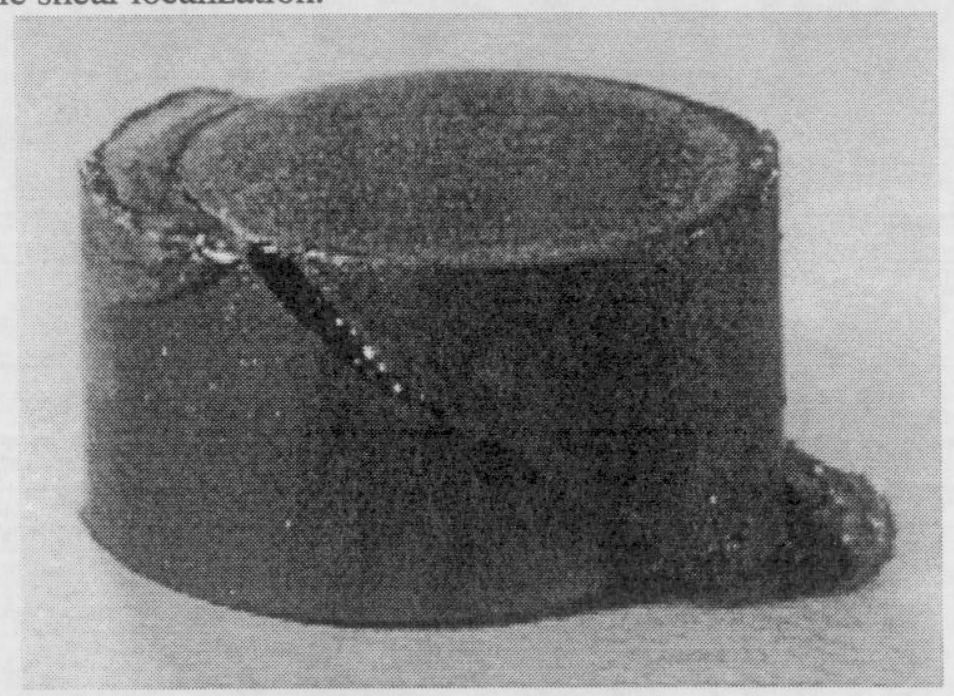

FIGURE 5. PHOTOGRAPH OF Ti-6Al-4V SAMPLE AFTER TESTING IN COMPRESSION.

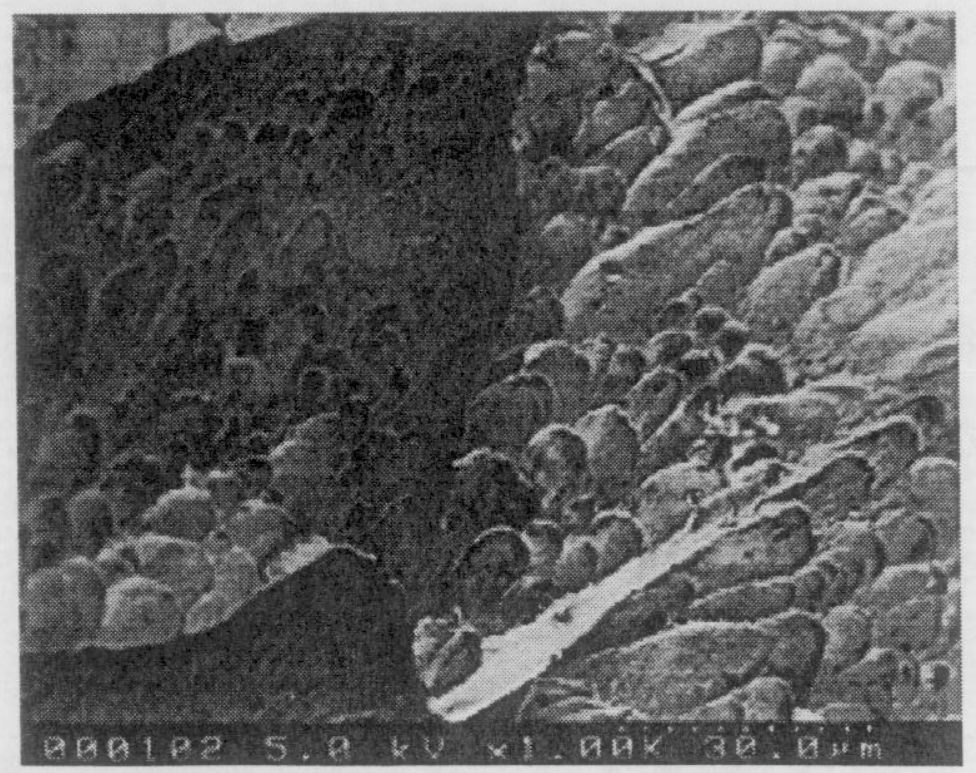

FIGURE 6. FRACTURE SURFACE OF Ti-6Al-4V SAMPLE TESTED IN COMPRESSION. 


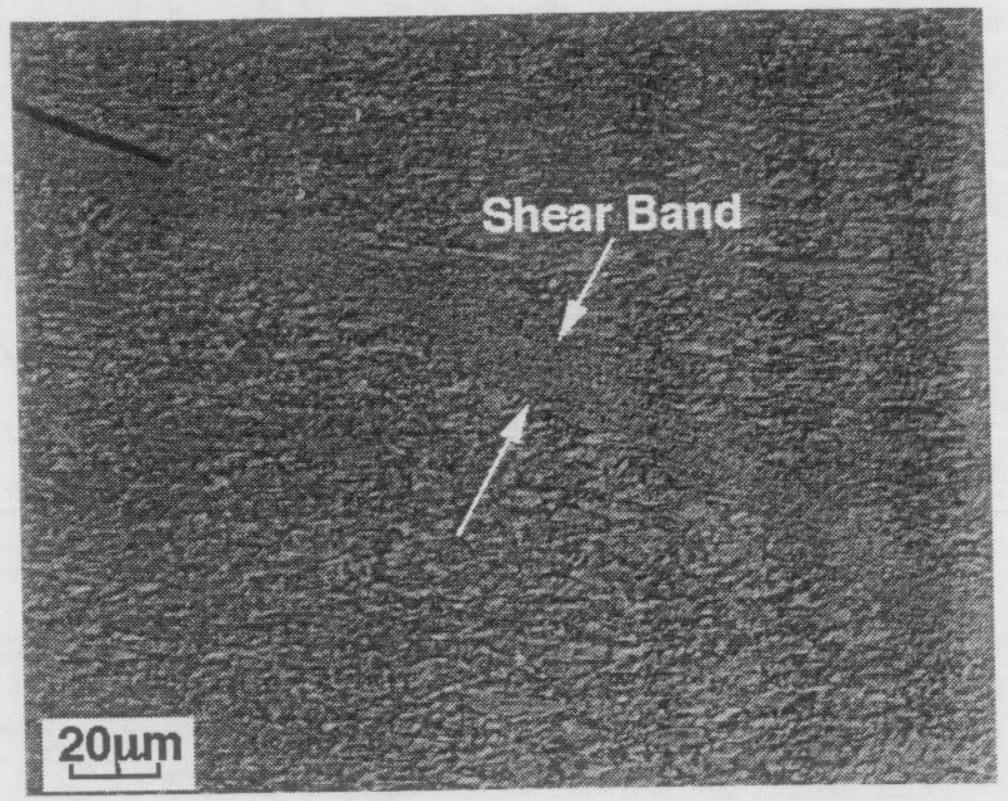

\section{FIGURE 7. SHEAR BAND IN Ti-6Al-4V SAMPLE AFTER TESTING IN COMPRESSION.}

The cross-section of a fractured tensile sample (tensile axis was parallel to the $0^{\circ}$ direction) is shown in Fig. 8. The normal and $0^{\circ}$ directions are indicated and the sample was observed to fail in shear with the shear fracture propagating through the thickness of the plate. Figure 9 shows the
fracture surface of the tensile sample tested with the tensile axis parallel to the $90^{\circ}$ direction. As with the compression sample, shallow voids are observed (about $5 \mu \mathrm{m}$ in diameter) that grew due to shear deformation. These fracture characteristics are representative of all tensile failures observed with the Ti-6Al-4V alloy. Fracture in both tension and compression was concluded to result from adiabatic shear localization. It is important to compare failure modes in the Hopkinson bar samples with the results of post-failure analysis conducted by Pratt \& Whitney on a Ti-6Al-4V fan case, which was impacted by a fan blade [12]. Both the Hopkinson bar samples reported here and the fan case study showed failures involving shear localization. In both cases, the width of the shear bands was observed to be approximately $15 \mu \mathrm{m}$.

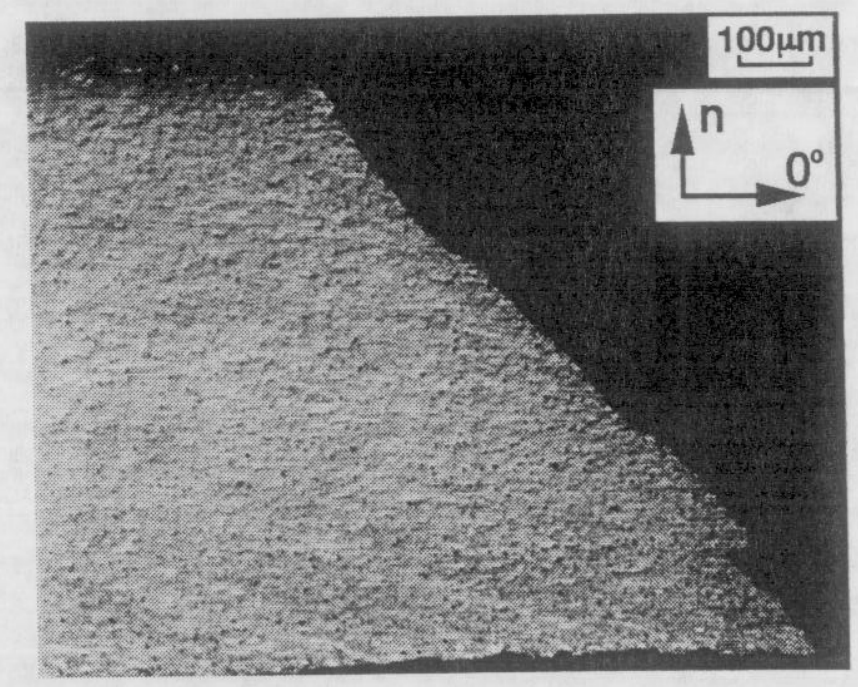

FIGURE 8. CROSS-SECTION OF Ti-6Al-4V SAMPLE AFTER TESTING IN TENSION. 


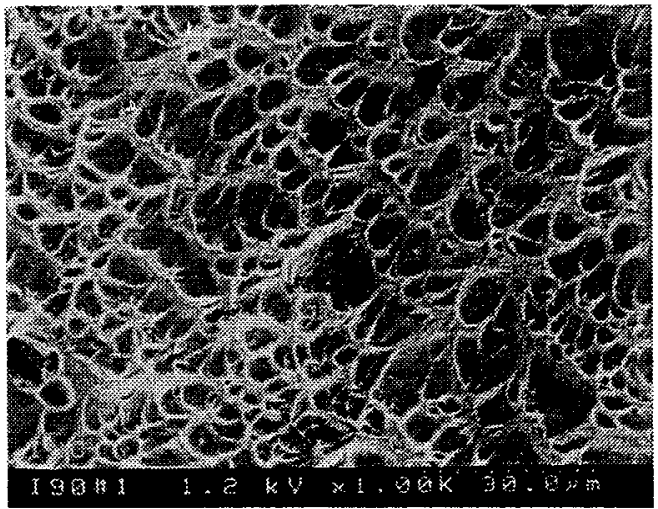

FIGURE 9. FRACTURE SURFACE OF Ti-6Al-4V SAMPLE TESTED IN TENSION.

\subsubsection{Data Analysis.}

The stress-strain response in tension and compression is compared in Fig. 10 for Ti-6Al-4V samples tested in the $0^{\circ}$ orientation. The results show that, in the region of valid data (large-scale plastic flow), the two curves coincide. Thus, for loading in the $0^{\circ}$ direction, the stress-strain behavior of the hot rolled Ti-6Al-4V alloy is insensitive to the sign of the applied stress (tension versus compression). In Section 2.3.1, it was noted that the flow behavior was isotropic in tension but anisotropic in compression. Analysis of Figs. 3, 4 and 6 shows that, with the exception of the $90^{\circ}$ orientation in compression, a common $\sigma-\varepsilon$ curve results. Thus, with the exception of this $90^{\circ}$ orientation, the stress-strain behavior of the Ti-6Al-4V alloy is isotropic and insensitive to mean stress, which is required for use of the JC material model. This common curve will be used in subsequent evaluations of the JC material model. As shown in the Appendix, the functional dependence of stress on strain at constant strain rate and temperature can be represented very well by a power law equation, as required by the JC material model.

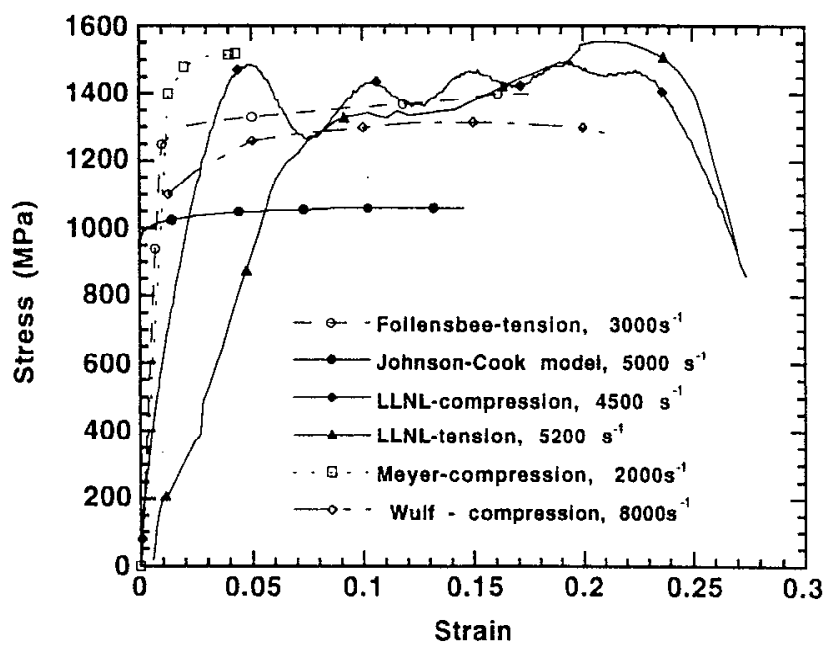

FIGURE 10. COMPARISON OF THE HIGH-STRAIN-RATE, STRESS-STRAINRESPONSE OF THE Ti-6Al-4V ALLOY IN TENSION ANDCOMPRESSION. DATA IS ALSO PROVIDED FOR OTHER HIGH-RATE STUDIES OF ANNEALED Ti6Al-4V FROM THE LITERATURE. THE PREDICTIONS OF THE JOHNSON-COOKMATERIAL MODEL USING THE ORIGINAL PARAMETERS ARE SHOWN IN THE FIGURE. 
It is useful to compare the results of the present study with stress-strain data obtained on "hot worked" and "annealed" Ti-6Al-4V by other investigators. Four-high-strain rate studies, which are of interest, are shown in Table 4. The type of tests conducted, material processing history and microstructure (as described by the investigators) are indicated in the table. The stress-strain data from these studies are compared with data from the present study in Fig. 10. The strain rates ranged from $2000 \mathrm{~s}^{-1}$ to $8000 \mathrm{~s}^{-1}$. The data for all studies fall within a tight band with a range of about $100 \mathrm{MPa}$. Of particular note is the investigation by Wulf [13], who studied Ti-6Al-4V processed to the AMS 4911 specification. Thus it appears that, despite slightly different compositions and processing histories, only relatively minor variations in the high-strain-rate, stress-strain behavior result. At quasi-static strain rates, the stress-strain response of Ti-6 Al-4V is influenced by microstructure, composition (including interstitial content) and texture with variations of $200 \mathrm{MPa}$ possible [11].

TABLE 4. HIGH RATE LITERATURE DATA FOR ANNEALED Ti-6Al-4V

\begin{tabular}{|c|c|c|c|}
\hline Investigators & Type of Tests & $\begin{array}{c}\text { Material Processing History / } \\
\text { Microstructure }\end{array}$ & Ref. \\
\hline Follansbee and Gray & $\begin{array}{c}\text { Hopkinson bar } \\
\text { (compression) }\end{array}$ & $\begin{array}{c}\text { Hot rolled plate } \\
\text { Equiaxed } \alpha(5 \mu \mathrm{m} \text { grain size) with } \\
\beta \text { at grain boundary triple points }\end{array}$ & {$[14]$} \\
\hline Meyer & $\begin{array}{c}\text { servohydraulic (tension and } \\
\text { compression); } \\
\text { impact pendulum (tension); } \\
\text { rotating wheel (tension); } \\
\text { drop weight (compression) }\end{array}$ & $\begin{array}{c}\text { Hot rolled bar, heat treated at } \\
700^{\circ} \mathrm{C}, 2 \text { hr, air cooled } \\
\text { Globular } \alpha\end{array}$ & {$[15]$} \\
\hline Wulf & $\begin{array}{c}\text { modified Hopkinson bar } \\
\text { (compression) }\end{array}$ & AMS 4911B & {$[13]$} \\
\hline Lee and Lin & $\begin{array}{c}\text { Hopkinson bar } \\
\text { (compression) } \\
\text { Tests done at 25, 700,900, } \\
1100^{\circ} \mathrm{C}\end{array}$ & Hot extruded bar & {$[16]$} \\
\hline Johnson & $\begin{array}{c}\text { Quasi-static tension; } \\
\text { Torsion; } \\
\text { Hopkinson bar (tension) }\end{array}$ & Unknown & {$[17$,} \\
\hline
\end{tabular}

Stress-strain rate data obtained from the various studies are shown in Fig. 11 on a semi-log plot. All data was obtained at a strain of .04 with the exception of the study by Wolf, which was obtained at a strain of .1. Below a strain rate of about $10^{3} \mathrm{~s}^{-1}$, the data follows a straight line. Thus, at these lower strain rates, there is a logarithmic dependence of stress on strain rate as required by the JC matcrial model. The logarithmic dependence of stress on strain rate is fundamentally justified in that obstacle-controlled plasticity, which is expected to dominate at low stresses and temperatures, has a logarithmic dependence of stress on strain rate [19]. At strain rates greater than $10^{3} \mathrm{~s}^{-1}$, however, the data shows a dramatic increase in strength with strain rate that can not be accounted for with this logarithmic dependence. This increase in strength has been obscrved in a number of metals (see, for example reference [20]) and is generally recognized as resulting from a change in deformation mechanism. At lower strain rates, the deformation rate is controlled by the cutting or by-passing of discrete obstacles by dislocations. At higher rates, the deformation rate is controlled by phonon or electron drag on moving dislocations. These two mechanisms are represented by different deformation rate equations [21], which produces the dramatic change in behavior on going from low strain rates to high strain rates. Such dramatic changes in behavior are outside the scope 
of the JC model. In our derivation of material parameters for the JC model, we use stress-strain rate data below strain rates of $10^{3}-10^{4} \mathrm{~s}^{-1}$.

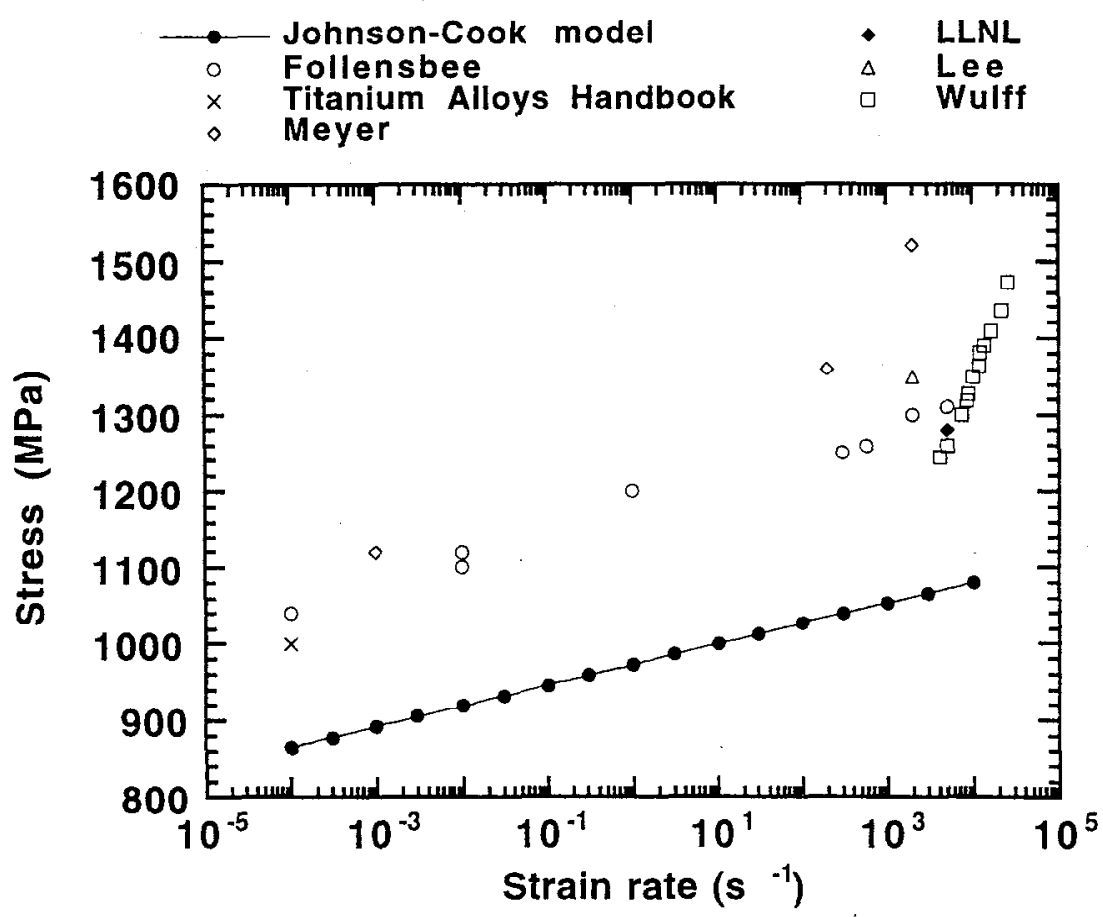

FIGURE 11. COMPARISON OF THE STRESS-STRAIN RATE RESPONSE OF Ti6A1-4V OBTAINED FROM THE THIS STUDY AS WELL AS OTHER STUDIES FROM THE LITERATURE. ALL DATA WAS OBTAINED AT A STRAIN OF .04 WITH THE EXCEPTION OF THE STUDY BY WULF, WHICH WAS OBTAINED AT A STRAIN OF .1. THE PREDICTIONS OF THE JOHNSON-COOK MATERIAL MODEL USING THE ORIGINAL PARAMETERS ARE ALSO SHOWN IN THE FIGURE.

It is important to recognize that at quasi-static strain rates (e.g. $10^{-4} \mathrm{~s}^{-1}$ ), the Ti-6Al-4V alloy is well known for exhibiting the so-called "strength differential effect", in which the flow stress in compression is higher than the flow stress in tension. The difference in flow stress can be quite large. For example, Lowden and Hutchinson [22] have reported that for Ti-6Al-4V annealed at $930^{\circ} \mathrm{C}$ and air cooled (microstructure consisted of primary alpha and transformed beta), the flow stress in the rolling direction was approximately $100 \mathrm{MPa}$ higher in compression than tension. In the transverse direction, the difference in flow stress could be as large as $900 \mathrm{MPa}$. Chait [23] has also reported a strength differential effect in Ti-6Al-4V. In this study, samples were annealed at $750^{\circ} \mathrm{C}$ and the difference in yield strength between tension and compression was about $85 \mathrm{MPa}$. However, in work by Meyer on hot rolled and annealed Ti-6 Al-4V [15], the strength differential effect was virtually absent. In this study, tests were done at strain rates of $10^{-3} \mathrm{~s}^{-1}$ and $200 \mathrm{~s}^{-1}$ and the maximum flow stress difference between tension and compression was less than $20 \mathrm{MPa}$. The observation of a strength differential effect appears to be very sensitive to relatively small variations in composition and processing. 


\subsubsection{Stress-Strain Data.}

\subsubsection{Compression}

The true stress-true strain response for the 2024-T3 alloy in compression is shown in Fig. 12. The nominal strain rate in these tests was $4000 \mathrm{~s}^{-1}$. Two tests are shown for each of the three testing orientations evaluated and the repeatability of the test data is excellent. As shown in the figure, both samples tested in the in-plane $0^{\circ}$ orientation had flow stresses that were slightly lower than the flow stresses for the in-plane $90^{\circ}$ and normal orientations (maximum deviation was $20 \mathrm{MPa}$ ). This deviation between stress-strain curves is very small and thus the stress-strain response can be considered isotropic. This is an important finding, since the JC material model assumes isotropic behavior. As mentioned in Section 2.3.1, the oscillations in the stress-strain curves are the result of obtaining data from the long elastic pressure bars. The stress-strain response of the sample is considerably more uniform and can be taken as the average curve through the data in Fig. 12. For the 2024-T3 samples tested in compression, the fracture strain could not be determined. The maximum strains shown for the stress-strain curves in Fig. 12 represent the limits at which reliable data were obtained. Considerably more deformation was put into the samples after the maximum strains shown in the figure without obvious fracture or dramatic loss in load bearing capability. The maximum strains obtained in Fig. 12 are recorded in Table 3.

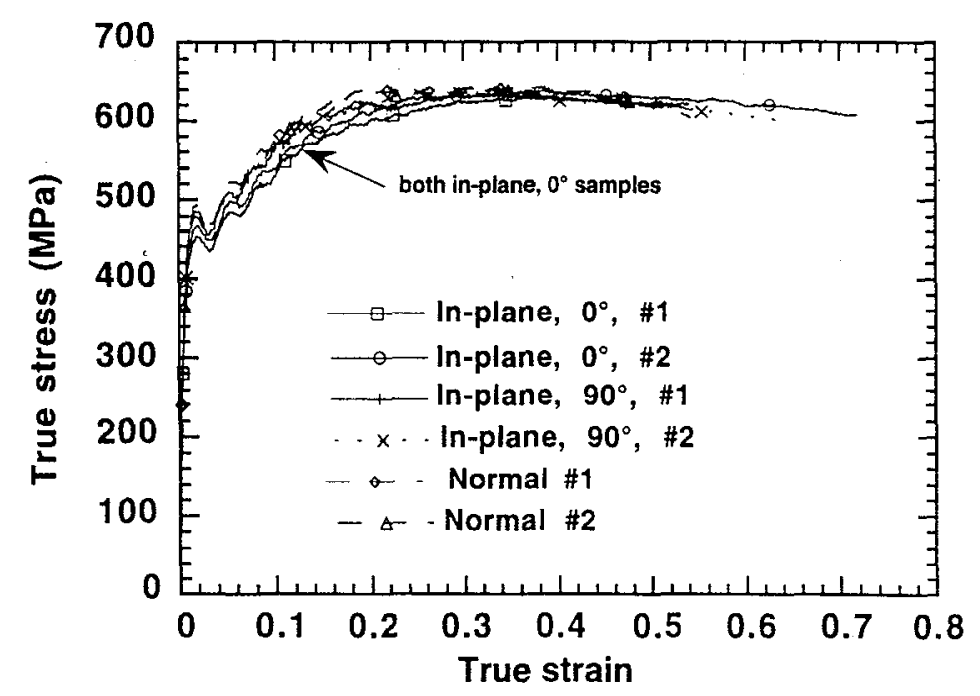

FIGURE 12. STRESS-STRAIN RESPONSE FOR 2024-T3 TESTED IN COMPRESSION AT A STRAIN RATE OF $4000 \mathrm{~s}^{-1}$.

\subsubsection{Tension}

The true stress-true strain response for the 2024-T3 alloy in tension is shown in Fig. 13. The nominal strain rate in these tests was $8000 \mathrm{~s}^{-1}$. Test results are shown for both in-plane orientations. The data for the two orientations virtually superimpose demonstrating that the tensile stress-strain response in the plane is isotropic. As discussed in Section 2.3.1, the stress-strain curves shown in Figs. 12 and 13 can be considered valid, once the samples have yielded plastically, which is accompanied by stress and strain rate uniformity in the sample. 


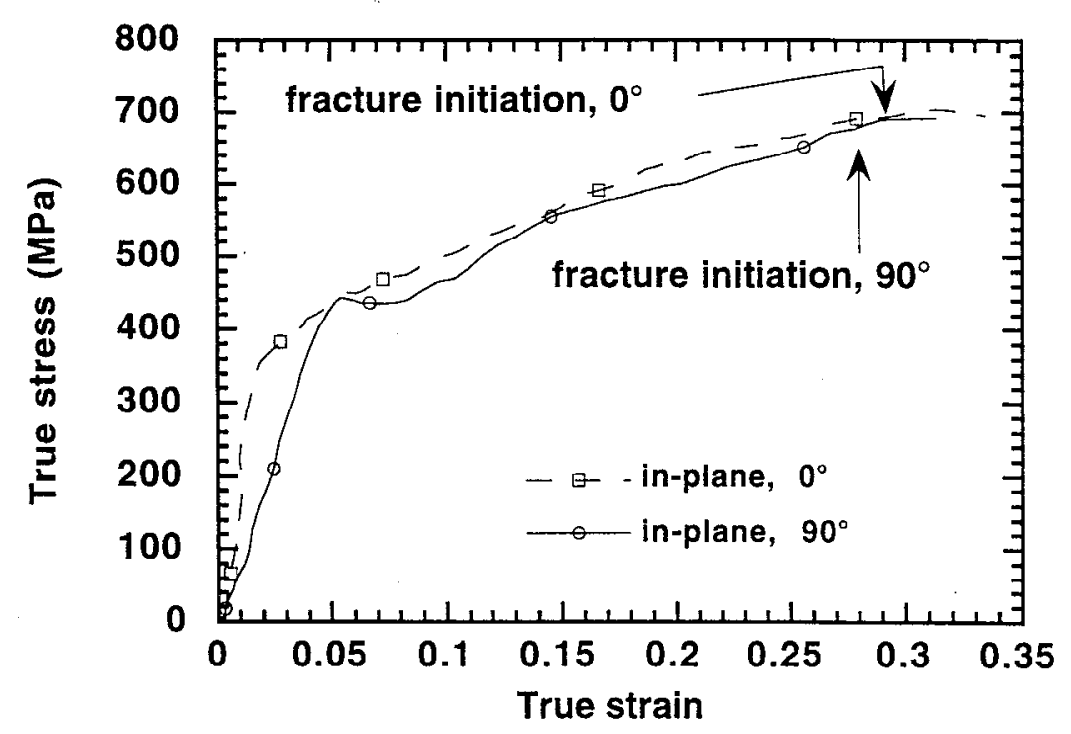

FIGURE 13. STRESS-STRAIN RESPONSE FOR 2024-T3 TESTED IN TENSION AT A STRAIN RATE OF $8000 \mathrm{~s}^{-1}$.

\subsubsection{Microstructural Characterization.}

As shown in Fig. 12, the 2024-T3 compression samples deformed to very large strains during testing. The deformation in these samples was so large that meaningful post-test characterization of the compression samples was not possible. The tensile samples had several, interconnected shear fractures in a given sample. Examination of the framing camera records revealed that the tensile samples failed without noticeable necking by initiation of cracking at the corners of the sample. The strains at which fracture was initiated are indicated in Fig. 13 and recorded in Table 3. For both tensile samples studied, fracture initiated at the maximum stress as shown on the stress-strain curves in Fig. 13.

\subsubsection{Data Analysis.}

Stress-strain curves in tension and compression for the 2024-T3 alloy are plotted on a common set of axes in Fig. 14. The tensile stress-strain curves include data obtained in both in-plane orientations. The results show that, in the region of valid data (large-scale plastic flow), the three curves coincide. Thus the stress-strain behavior of the 2024-T3 alloy is insensitive to the sign of the applied stress (tension versus compression). In section 2.4.1 we noted that the material is also extremely isotropic. Thus, we will assume that the stress-strain behavior of the 2024-T3 alloy is isotropic and insensitive to mean stress, which is required for use of the JC material model.

The stress-strain curves in compression show a maximum stress at a strain of about .3. O-Donnell and Woodward [24] have estimated the thermal softening in the 2024 alloy due to adiabatic heating and found that a maximum in the stress-strain curve is expected at a strain of .27 . Thus the maximum shown in the stress-strain curves in Fig. 12 should be associated with adiabatic heating effects and not associated with the initiation of an instability (shear bands). Previous studies of shear localization have shown that a maximum in the stress-strain curve is a necessary but not sufficient condition for shear localization [Semiatin, 1981 \#46; Semiatin, 1983 \#45]. Indeed, noticeable amounts of shear softening must occur before flow localization occurs. 


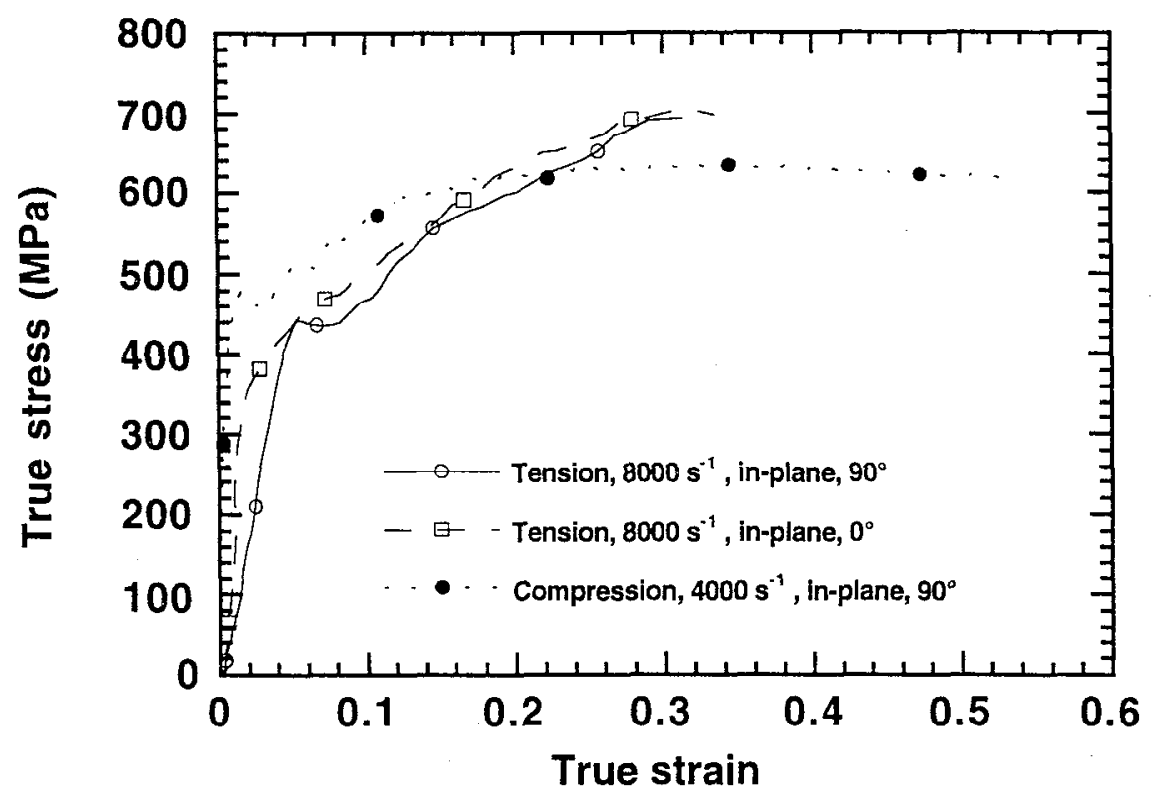

FIGURE 14. COMPARISON OF THE HIGH-STRAIN-RATE, STRESS-STRAIN RESPONSE OF 2024-T3 IN TENSION AND COMPRESSION.

The data reported here represent the first published studies of the high-rate, stress-strain response of 2024-T3. Data has been reported for the 2024 alloy in the T351 temper $[9,24,25]$. Both the T3 and T351 tempers designate material that has been solution heat-treated, cold-worked and naturally aged. The T3 temper applies to flat sheet material that is less than $6.3 \mathrm{~mm}$ thick, whereas the T351 temper applies to plate material that is greater than $6.3 \mathrm{~mm}$ thick. For plate thickness less than 51 $\mathrm{mm}$ thick, data reported in the Aerospace Structural Metals Handbook [26] and the Source Book on Industrial Alloy and Engineering Data [27] show that the yield and ultimate tensile strengths in the two tempers are virtually identical. Data taken on 2024-T351 is thus a valuable source of information for our analysis of the 2024-T3 alloy. Shear stress-shear strain data on the 2024-T351 alloy in torsion has been reported by Johnson et al. [9], Lindholm and Johnson [25] and Johnson and Holmquist [18] for shear strain rates from .088 s $\mathrm{s}^{-1}$ to $123 \mathrm{~s}^{-1}$. Each of these references reports the same data set, which consists of 6 torsion tests. The parameters for the JC material model reported in the next section were derived from these six tests on the 2024-T351 alloy.

O'Donnell and Woodward have studied the development of shear bands in 2024-T351 plate during compression testing [24]. A drop weight tower was used and initial strain rates of $600 \mathrm{~s}^{-1}$ were obtained. Tests were conducted in the rolling $\left(0^{\circ}\right)$, transverse $\left(90^{\circ}\right)$ and through thickness directions (normal) at temperatures from $0^{\circ} \mathrm{C}$ to $90^{\circ} \mathrm{C}$. The strains at which instabilities were observed (drops in the in the load-displacement records) are reported in Table 5 for the tests conducted at $20^{\circ} \mathrm{C}$. These instabilities were associated with intense shear bands and cracking within these bands. For practical purposes, these strains can be considered as failure strains for the 2024T351 alloy in compression, since sufficient flow localization and cracking occurred to cause abrupt losses in loading bearing capacity. The variations in the instability strains can be attributed to the inherent inhomogeneous distribution of inclusions, which are the origins of fracture, as well as variations in shcar band width. 
TABLE 5. INSTABILITY STRAINS FOR 2024-T351 IN COMPRESSION (REF. [241)

\begin{tabular}{|c|c|c|}
\hline Orientation & Test & Instability strain \\
\hline $0^{\circ}$ (rolling direction) & 1 & 0.87 \\
\hline $90^{\circ}$ (transverse direction) & 1 & 0.79 \\
& 2 & 0.74 \\
\hline Through thickness (normal) & 1 & 0.76 \\
& 2 & 0.70 \\
& 3 & 0.70 \\
& 4 & 0.85 \\
\hline
\end{tabular}

\section{ANALYSIS OF JOHNSON-COOK MATERIAL MODEL.}

The JC parameters for the Ti-6Al-4V alloy were reported by Johnson [17] as part of a study for the Naval Surface Weapons Center (NSWC). The parameters are provided in Table 6. The parameter were based on 8 torsion tests, 4 Hopkinson bar tests and 2 quasi-static tensile tests. In Fig. 15, the stress-strain rate curve predicted from the JC model at a strain of .002 is compared against some of the original data reported by Johnson $[17,18]$. The rapid increase in strength at the higher strain rates mentioned in Section 2.3.3 is evident in this data set. The torsion data (provided as shear stress versus shear strain at several shear strain rates) was converted to effective (von Mises) quantities using the following expressions

$$
\begin{aligned}
& \sigma=\sqrt{3} \tau \\
& \varepsilon=\gamma / \sqrt{3} \\
& \dot{\varepsilon}=\gamma / \sqrt{3}
\end{aligned}
$$

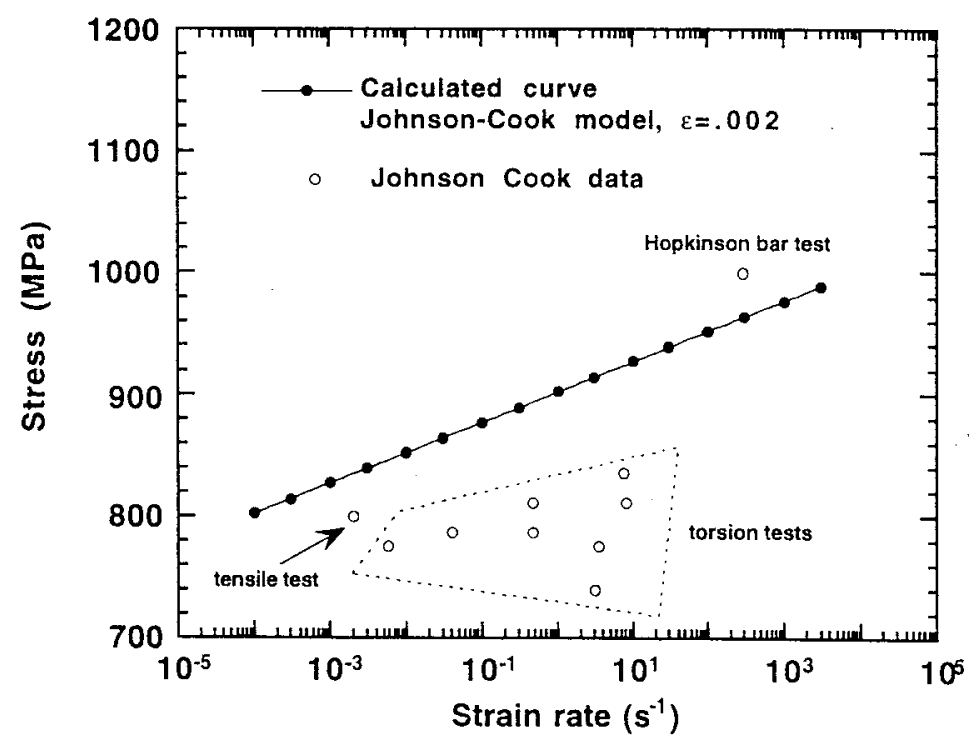

FIGURE 15. STRESS-STRAIN RATE DATA OBTAINED BY JOHNSON FOR THE Ti-6Al-4V ALLOY AT A PLASTIC STRAIN OF .002. THE PREDICTIONS OF THE JOHNSON-COOK MODEL USING THE ORIGINAL PARAMETERS ARE ALSO SHOWN IN THE FIGURE. 
The Ti-6Al-4V alloy was identified as having been "provided by NSWC". No processing history or microstructural characterization was provided in the report. However, the hardness was quoted as Rc 29, which is extremely low for Ti-6Al-4V. A typical hardness value for the Ti-6Al-4V alloy processed to the AMS 4911 specification would be Rc 36 [27]. The parameters for the JC model reported by Johnson reflect the low hardness (strength) of the alloy that was evaluated. The predicted adiabatic stress - strain curve was calculated using Equations 1,2 and 3 and assuming that $100 \%$ of the plastic work is transformed into heat $(\alpha=1)$. The physical properties used in these calculations are shown in Table 7 . The predicted adiabatic stress-strain response at a strain rate of $5000 \mathrm{~s}^{-1}$ using these original set of $\mathrm{JC}$ parameters is shown in Fig. 10. As expected, the predicted stress-strain curve is significantly softer than any of the experimental data for annealed Ti-6Al-4V. The stress-strain rate response predicted by the JC model is shown in Fig. 11 for a strain of .04. The calculations were done using the original JC parameters provided in Table 6. The predicted curve is significantly softer than experimental data. In addition, the inability of the model to capture the rapid increase in strength at the high strain rates is clearly evident.

The original JC parameter for the 2024-T351 alloy $[9,25]$ were determined on the basis of six torsion tests with strain rates ranging from $.088 \mathrm{~s}^{-1}$ to $123 \mathrm{~s}^{-1}$. These parameters are provided in Table 6. In the next section, a new set of JC parameters are provided and evaluated for the strengthcomponent of the JC model for both Ti-6Al-4V and 2024-T3.

TABLE 6. ORIGINAL PARAMETERS FOR JOHNSON-COOK MATERIAL MODEL

\begin{tabular}{|c|c|c|c|c|c|c|c|c|c|c|}
\hline & $\begin{array}{c}\mathrm{A} \\
(\mathrm{MPa})\end{array}$ & $\begin{array}{c}\mathrm{B} \\
(\mathrm{MPa})\end{array}$ & $\mathrm{n}$ & $\mathrm{C}$ & $\mathrm{m}$ & $\mathrm{D}_{1}$ & $\mathrm{D}_{2}$ & $\mathrm{D}_{3}$ & $\mathrm{D}_{4}$ & $\mathrm{D}_{5}$ \\
\hline $\mathrm{Ti}-6 \mathrm{Al}-4 \mathrm{~V}$ & 862 & 331 & .34 & .012 & .8 & -0.09 & 0.25 & -0.5 & .014 & 3.87 \\
\hline $2024-\mathrm{T} 351$ & 265 & 426 & .34 & .015 & 1 & 0.13 & 0.13 & -1.5 & .011 & 0.0 \\
\hline
\end{tabular}

TABLE 7. PHYSICAL PROPERTIES OF Ti-6Al-4V and 2024-T3

\begin{tabular}{|c|c|c|c|}
\hline & $\begin{array}{c}\text { Melting Temperature } \\
\left({ }^{\circ} \mathrm{C}\right)[\text { reference] }\end{array}$ & $\begin{array}{c}\text { Density } \\
\left(\mathrm{kg} / \mathrm{m}^{3}\right)[\text { reference }]\end{array}$ & $\begin{array}{c}\text { Heat Capacity } \\
(\mathrm{J} / \mathrm{kg} \mathrm{K}) \text { [refercnce] }\end{array}$ \\
\hline Ti-6Al-4V & $1605[11]$ & $4428[11]$ & $580[11]$ \\
\hline $2024-\mathrm{T} 3$ & $502[28]$ & $2770[28]$ & $875[28]$ \\
\hline
\end{tabular}

4. NEW CONSTANTS FOR JOHNSON-COOK MATERIAL MODEL.

4.1 Ti-6Al-4V

A new set of parameters for both $\mathrm{Ti}-6 \mathrm{Al}-4 \mathrm{~V}$ and 2024-T3 were determined for the strength component of the JC model using the procedures outlined in Appendix A. For both alloys, the A, B and $\mathrm{n}$ parameters were determined using the LLNL Hopkinson bar data. Data from the literature and the LLNL data were used to determine $\mathrm{C}$ and $\mathrm{m}$. The new parameters are provide in Table 8 . The predictions of the JC model for Ti-6Al-4V with these new constants are compared with experimental data in Figs. 16 - 19. Figures 16 and 17 compare the stress-strain response with experimental data at a high strain rate and a low strain rate respectively. The low rate data was obtained from the Ti Alloys Handbook [29]. Figures 18 and 19 compare the stress-strain rate response and the stress-temperature response, respectively, with experimental data. The stress temperature response was considered at both high strain rates $\left(2500 \mathrm{~s}^{-1}\right)$ and low strain rates $\left(10^{-4} \mathrm{~s}^{-}\right.$ $\left.{ }^{1}\right)$. The high rate data was obtained from the work of Lee and Lin [16] at three strains and the low 
rate data was obtained from the Aerospace Structural Materials Handbook [30] and the Titanium Alloys Handbook [29]. The stress versus temperature data is provided in Fig. A3 and the high rate data was used to establish the $\mathrm{m}$ parameter.

TABLE 8. NEW PARAMETERS FOR JOHNSON-COOK MATERIAL MODEL

\begin{tabular}{|c|c|c|c|c|c|c|c|c|c|c|}
\hline & $\begin{array}{c}\mathrm{A} \\
(\mathrm{MPa})\end{array}$ & $\begin{array}{c}\mathrm{B} \\
(\mathrm{MPa})\end{array}$ & $\mathrm{n}$ & $\mathrm{C}$ & $\mathrm{m}$ & $\mathrm{D}_{1}$ & $\mathrm{D}_{2}$ & $\mathrm{D}_{3}$ & $\mathrm{D}_{4}$ & $\mathrm{D}_{5}$ \\
\hline Ti-6Al-4V & 1098 & 1092 & .93 & .014 & 1.1 & -0.09 & 0.25 & -0.50 & 0.014 & 3.87 \\
\hline $2024-\mathrm{T} 3$ & 369 & 684 & .73 & .0083 & 1.7 & 0.13 & 0.13 & -1.5 & 0.011 & 0.0 \\
\hline
\end{tabular}

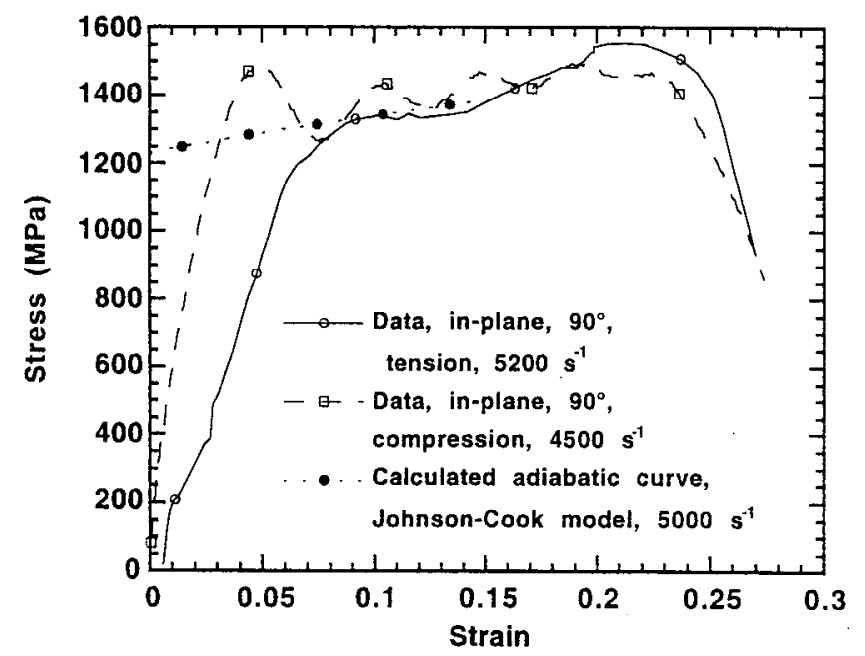

FIGURE 16. COMPARISON OF THE HIGH-STRAIN-RATE, STRESS-STRAIN RESPONSE OF THE Ti-6Al-4V ALLOY PREDICTED BY THEJOHNSONCOOK MATERIAL MODEL (USING THE NEW MATERIAL PARAMETERS) WITH EXPERIMENTAL DATA IN TENSION AND COMPRESSION.

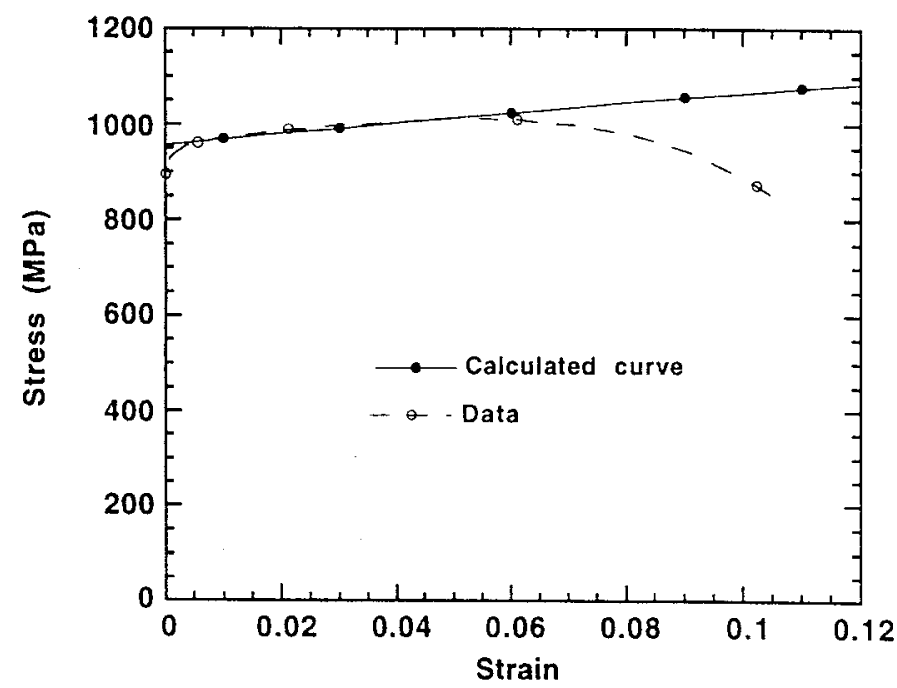

FIGURE 17. COMPARISON OF THE LOW-STRAIN-RATE $\left(.0001 \mathrm{~s}^{-1}\right)$, STRESS-STRAIN RESPONSE OF THE Ti-6Al-4V ALLOY AS PREDICTED BY THE JOHNSONCOOK MATERIAL MODEL (USING THE NEW MATERIAL PARAMETERS) WITH EXPERIMENTAL DATA IN TENSION. 


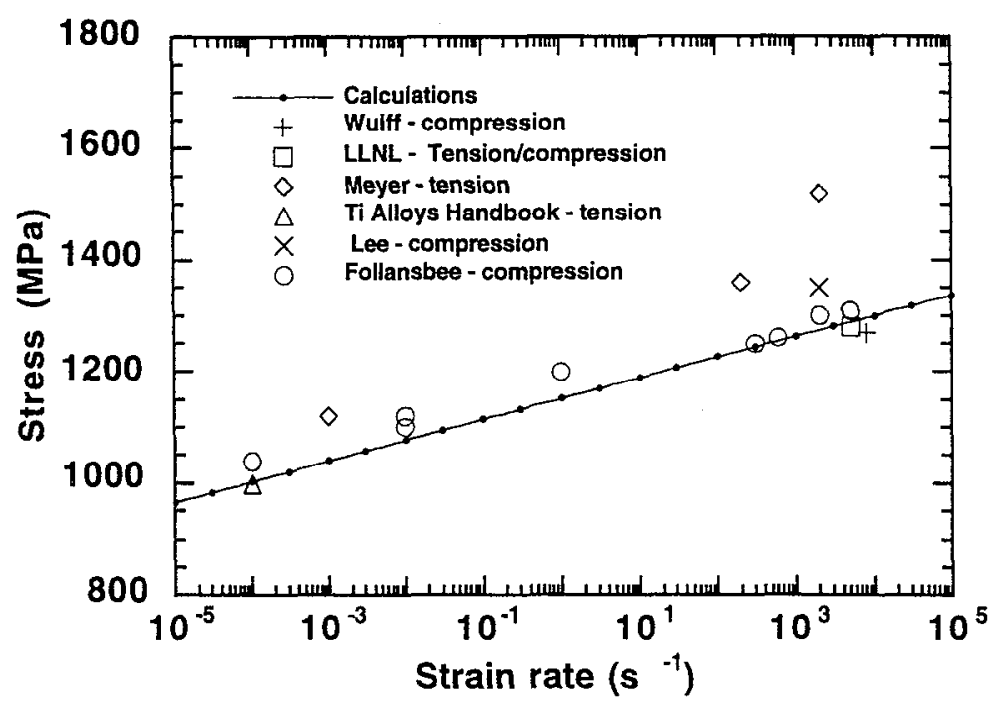

FIGURE 18. COMPARISON OF THE STRESS-STRAIN RATE RESPONSE OF THE Ti-6Al-4V ALLOY AS PREDICTED BY THE JOHNSON-COOK MATERIAL MODEL (USING THE NEW MATERIAL PARAMETERS) WITH EXPERIMENTAL DATA. CALCULATIONS AND DATA WERE TAKEN AT A STRAIN OF .04.
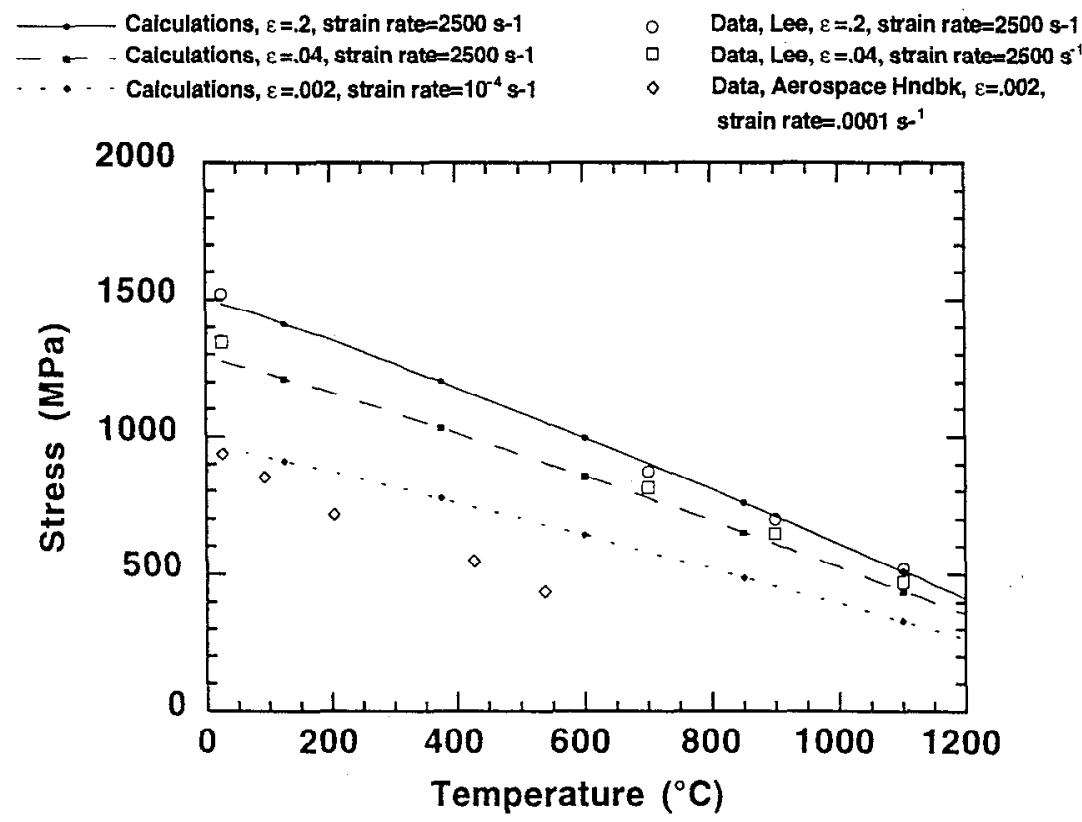

FIGURE 19. COMPARISON OF THE STRESS-TEMPERATURE RESPONSE OFTHE Ti-6Al-4V ALLOY AS PREDICTED BY THE JOHNSON-COOK MATERIAL MODEL (USING THE NEW MATERIAL PARAMETERS) WITH EXPERIMENTAL DATA. 
Examination of Figs 16-19 provides the following assessment of the capabilities and limitations of the strength component of the JC model with the new parameters.

a) Stress-strain behavior. The model can accurately represent the yield and plastic flow behavior of Ti-6Al-4V at both low and high strain rates with a single set of material constants. The model does not account for anisotropy which can produce flow stress differences of approximately $250 \mathrm{MPa}$ (Fig. 3) in Ti-6Al-4V processed to the 4911 specification. However, anisotropy was only observed in the $90^{\circ}$ orientation, compression experiments. Other orientations and testing modes showed isotropic behavior. For practical utilization of this material model, limitations resulting from anisotropy are considered to be relatively minor.

b) Stress-strain rate behavior. Below a strain rate of $10^{3} \mathrm{~s}^{-1}$, the model can adequately represent the stress - strain rate response of the alloy. Above $10^{3} \mathrm{~s}^{-1}$, flow stresses can increase sharply with increasing strain rate due to a change in deformation mechanism as discussed in Section 2.3.3. These higher strain rates are of primary interest to simulations involving engine containment and the influence of uncontained engine debris on aircraft structures. Examination of Fig. 18 suggests that the strain rate at which the rapid increase in flow stresses occurs is sensitive to composition and processing. For the data of Wulf (processed to the 4911 specification), the model predicts flow stresses at a strain rate of $20,000 \mathrm{~s}^{-1}$ that are about $150 \mathrm{MPa}$ low.

c. Stress-temperature behavior. Figure 19 shows that at high strain rates the stress - temperature response can be represented very well by the model. At low strain rates, however, the model predicts stresses that are significantly higher than observed experimentally (e.g. $250 \mathrm{MPa}$ high at $500^{\circ} \mathrm{C}$ ). Clearly the temperature term is influenced by strain rate (or stress). Other constitutive equations, such as in the mechanical threshold stress model, account for the influence of stress on thermal activation and thus temperature dependence. For our purposes, the JC model can be considered adequate if the $\mathrm{m}$ parametcr is cvaluated in the high strain rate range.

The adiabatic stress-strain response for Ti-6Al-4V at $5000 \mathrm{~s}^{-1}$ predicted by the JC material model using the new strength parameters is shown in Fig. 20. Results are shown for loading in tension, shear and compression. The predicted failure strains and resulting temperature rise in the samplc are shown in the figure. The calculations assume uniform deformation and $100 \%$ of the mechanical work is dissipated as heat. The results predict a $110^{\circ} \mathrm{C}$ increase in temperature in tension and $140^{\circ} \mathrm{C}$ increase in temperature in compression. The failure strains observed in the Hopkinson bar tests for Ti-6Al-4V (reported in Table 3) show that at high strain rates $\left(5000 \mathrm{~s}^{-1}\right)$ the failure strain is independent of pressure and equal to .2 The results in Fig. 20 show that the failure strains predicted with the damage constants given in Table 8 have a mild pressure dependence. A better representation of the experimental data would thus be obtained if the damage parameter $D_{2}$ were 0 . A complete analysis of failure would require consideration of the failure mode (shear localization) as well as the influence of strain rate and temperature. Failure in the Ti-6Al-4V alloy will be considered further in a future report.

\subsection{4-T3}

The predictions of the JC model for 2024-T3 with these new constants are compared with experimental data in Figs. 21 - 24. Figures 21 and 22 compare the stress-strain response with experimental data at a high strain rate and a low strain rate respectively. The low rate data was obtained from the Aerospace Structural Materials Handbook [30] and the ASM International Handbook [31]. Figures 23 and 24 compare the stress-strain rate response and the stresstemperature response, respectively, with experimental data. Data for the stress-temperature response was available at low strain rates $\left(10^{-4} \mathrm{~s}^{-1}\right)$ only [31]. The results in Figs $21-24$ show that the strength component of the JC model with the new parameters can represent the stress-strainstrain rate-temperature response of 2024-T3 very well. The major concern with the JC model is its 
ability to accurately represent the stress-strain rate response of 2024-T3 at higher strain rates than studied here. Theory predicts that, as with Ti-6Al-4V, the stress will increase sharply at higher strain rates (e.g. greater than $10^{4} \mathrm{~s}^{-1}$ ) in a manner that can not be accounted for by the logarithmic dependence of stress on strain rate that is shown in Fig. 23. Indeed, work with other aluminum alloys (e.g. 6061-T6 [32]) has shown that sharp increases in strength are observed at strain rates greater than $10^{3} \mathrm{~s}^{-1}$.

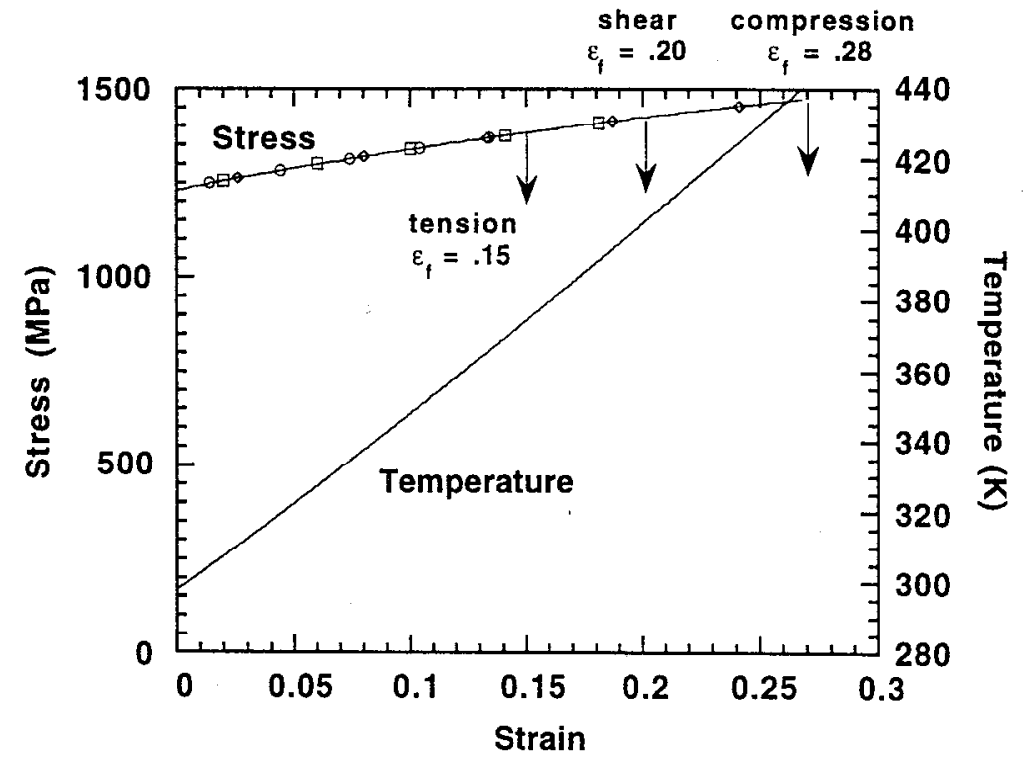

FIGURE 20. PREDICTED ADIABATIC STRESS-STRAIN RESPONSE FOR THE Ti-6Al-4V ALLOY IN TENSION, SHEAR AND COMPRESSION AT A STRAIN RATE OF $5000 \mathrm{~s}^{-1}$. THE PREDICTED FALLURE STRAINS AND RESULTING TEMPERATURE RISE IN THE SAMPLE ARE SHOWN IN THE FIGURE.

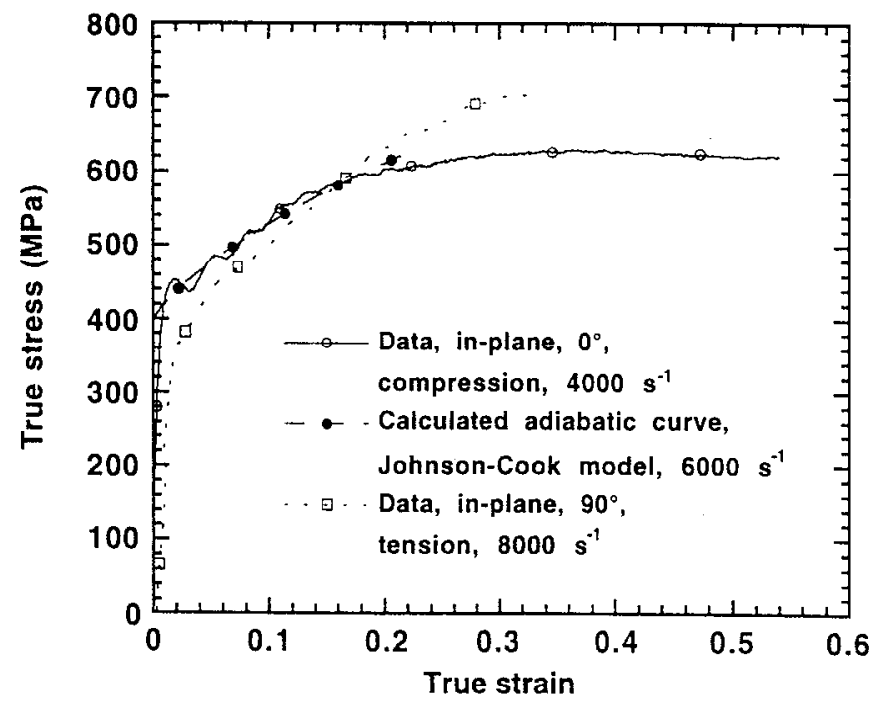

FIGURE 21. COMPARISON OF THE HIGH-STRAIN-RATE, STRESS-STRAIN RESPONSE OF THE 2024-T3 ALLOY PREDICTED BY THE JOHNSONCOOK MATERIAL MODEL (USING THE NEW MATERIAL PARAMETERS) WITH EXPERIMENTAL DATA INTENSION AND COMPRESSION. 


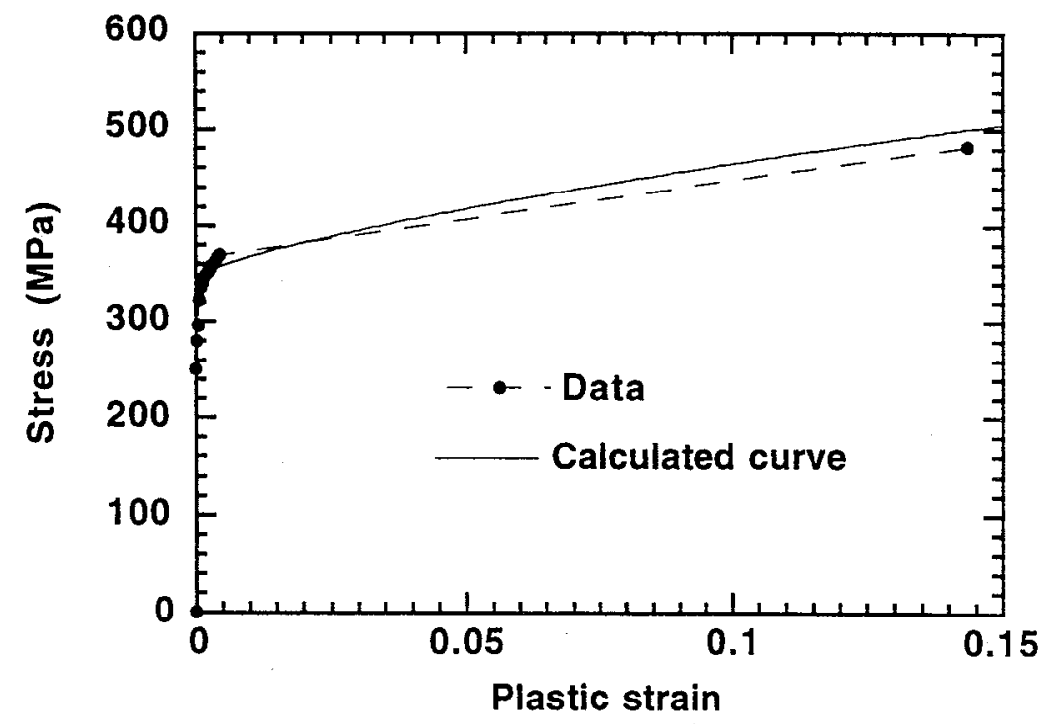

FIGURE 22. COMPARISON OF THE LOW-STRAIN-RATE $\left(.0005 \mathrm{~s}^{-1}\right)$, STRESS-STRAIN RESPONSE OF THE 2024-T3 ALLOY AS PREDICTED BY THE JOHNSONCOOK MATERIAL MODEL (USING THE NEW MATERIAL PARAMETERS) WITH EXPERIMENTAL DATA IN TENSION.

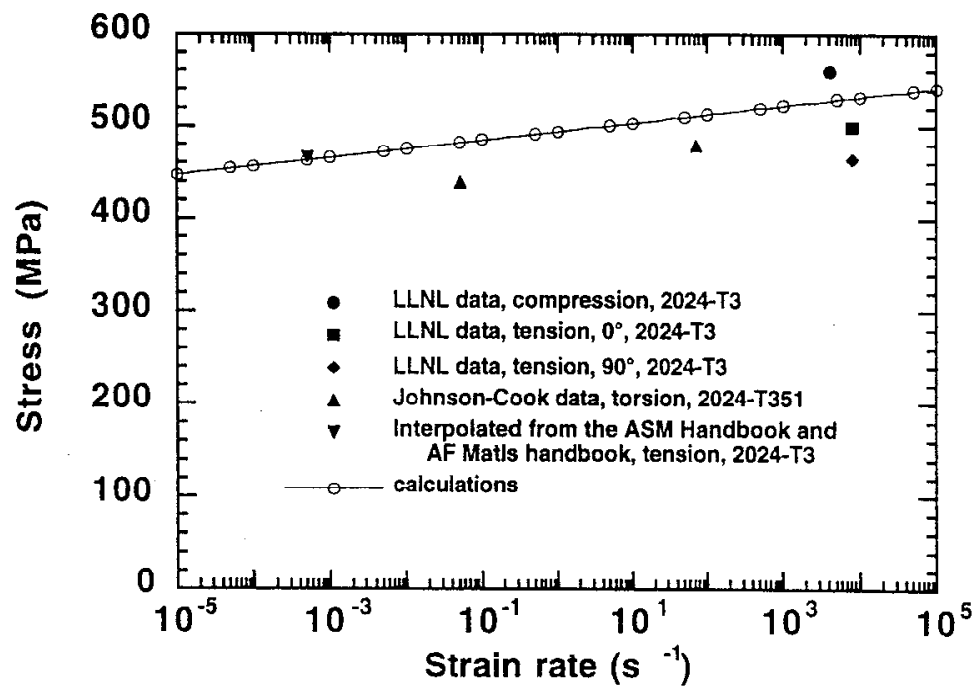

FIGURE 23. COMPARISON OF THE STRESS-STRAIN RATE RESPONSE OF THE 2024-T3 ALLOY AS PREDICTED BY THE JOHNSON-COOK MATERIAL MODEL (USING THE NEW MATERIAL PARAMETERS) WITH EXPERIMENTAL DATA. CALCULATIONS AND DATA WERE TAKEN AT A STRAIN OF .1. 


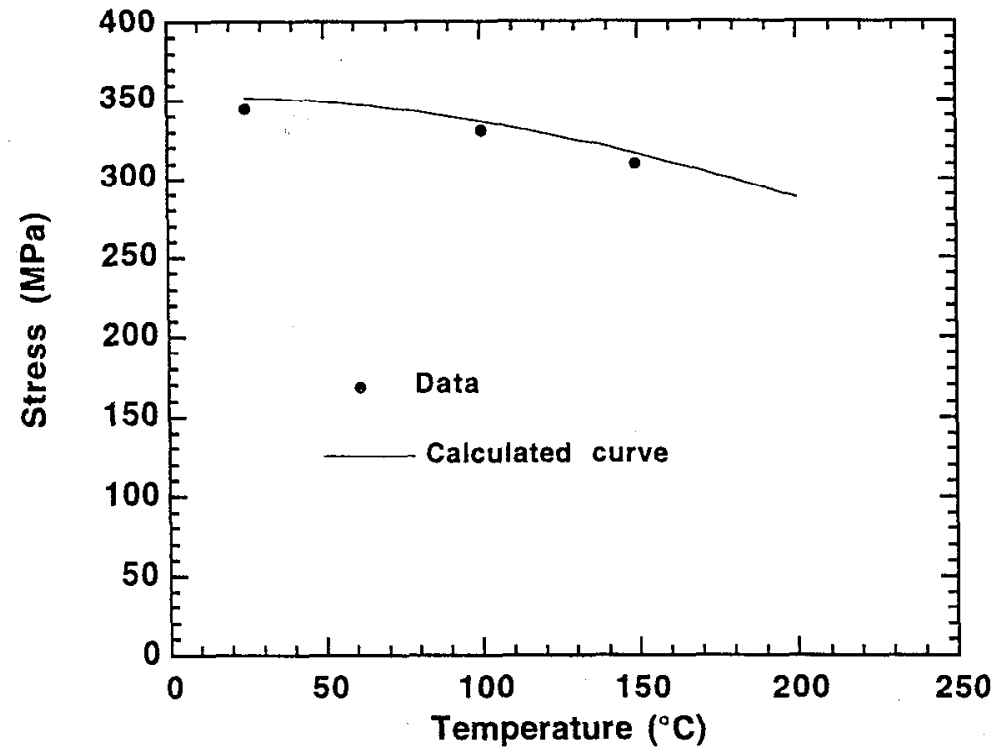

FIGURE 24. COMPARISON OF THE STRESS-TEMPERATURE RESPONSE OF THE 2024-T3 ALLOY AS PREDICTED BY THE JOHNSON-COOK MATERIAL MODEL (USING THE NEW MATERIAL PARAMETERS) WITH EXPERIMENTAL DATA. CALCULATIONS AND DATA WERE TAKEN AT A STRAIN RATE OF .0005 $\mathrm{s}^{-1}$ AND A STRAIN OF .002.

The adiabatic stress-strain response for 2024-T3 at $6000 \mathrm{~s}^{-1}$ predicted by the JC material model using the new strength parameters is shown in Fig. 25. Results are shown for loading in tension, shear and compression. The predicted failure strains and resulting temperature rise in the sample are shown in the figure. The calculations assume uniform deformation and $100 \%$ of the mechanical work is dissipated as heat. The results predict a $70^{\circ} \mathrm{C}$ increase in temperature in tension and $90^{\circ} \mathrm{C}$ increase in temperature in compression. Tables 3 and 5 show that, for the 2024-T3 alloy, failure in tension occurs at a strain of .3 , whereas failure in compression occurs at a strain of .8. Thus the experimental data at high strain rates shows a much stronger pressure dependence than shown in Fig. 25. The damage parameters used in these calculations were established by Lindholm and Johnson [25] and Johnson, Hoegfeldt, and Nagy [9] on the basis of torsion tests only with strain rates from $.088 \mathrm{~s}^{-1}$ to $123 \mathrm{~s}^{1}$. As with the Ti-6Al-4V alloy, a complete analysis of failure would require consideration of the failure mode (shear localization). Failure in the 2024-T3 alloy will be considered further in a future report.

\section{SUMMARY.}

The high strain rate, large strain deformation and fracture response of Ti-6Al-4V and 2024-T3 were evaluated using the split Hopkinson pressure bar technique. Both materials were processed to specifications appropriate for aircraft/engine designs. The stress-strain-strain rate data, plus additional data from the literature, was used to critically evaluate the ability of the JC model to represent the deformation and failure response of these materials under conditions relevant to simulations of engine containment and the influence of uncontained engine debris on aircraft structures. The results were used to define a new set of material constants for the JC model. For both materials, fracture occurred by shear localization. For Ti-6Al-4V, fracture features observed in the Hopkinson bar samples were comparable to fracture features observed during post-failure analysis of a Ti-6Al-4V fan case, which was impacted by a fan blade. Both failures occurred by shear localization. 


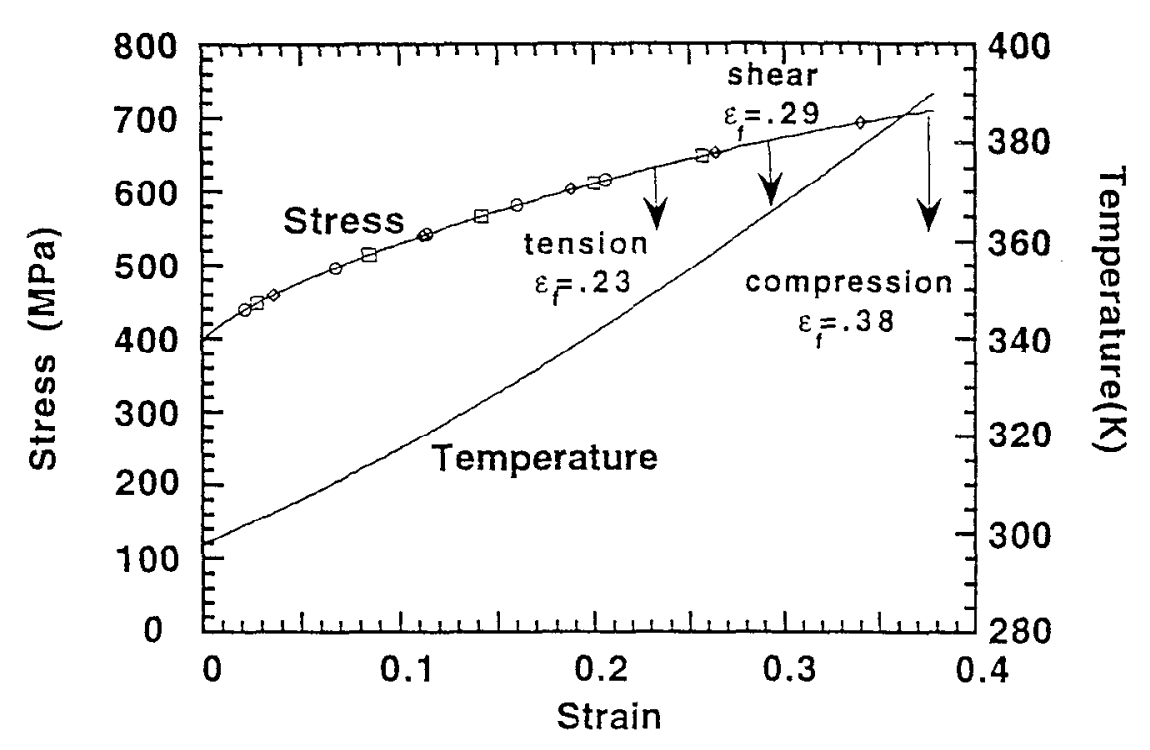

FIGURE 25. PREDICTED ADIABATIC STRESS-STRAIN RESPONSE FOR THE 2024-T3 ALLOY IN TENSION, SHEAR AND COMPRESSION AT A STRAIN RATE OF $6000 \mathrm{~s}^{-1}$. THE PREDICTED FAILLURE STRAINS AND RESULTING TEMPERATURE RISE IN THE SAMPLE ARE SHOWN IN THE FIGURE.

The results and analysis provided in the previous sections for both Ti-6Al-4V and 2024-T3 show that the JC model can accurately represent the stress-strain response of the materials. Other aspects of material behavior, such as plastic anisotropy and the influence of temperature, are not expected to adversely affect the use of the material model for high strain rate deformation and fracture problems. The major concern with the Johnson Cook material model is its ability to accurately represent the stress-strain rate response at strain rates greater than $10^{3}-10^{+} \mathrm{s}^{-1}$. For both materials, the deformation mechanism changes. The two mechanisms are represented by different deformation rate equations, which produces the dramatic change in behavior on going from low strain rates to high strain rates. Such dramatic changes in behavior are outside the scope of the JC model. The models and damage constants available in the literature also do not predict the correct failure strains. Adequate models for failure should account for shear localization.

\section{ACKNOWLEDGMENTS.}

The authors are indebted to Mary LeBlanc for the split Hopkinson pressure bar testing and Robert Kershaw for metallography.

\section{REFERENCES.}

1. Johnson, G. R. and W. H. Cook, "A Constitutive Model and Data for Metals Subjected to Large Strains, High Rates and High Temperatures," in Proceedings of the Seventh International Symposium on Ballistics, The Netherlands, The Hague, pp. 541-547, 1983. 
2. Johnson, G. R. and T. J. Holmquist, "Evaluation of Cylinder-Impact Test Data for Constitutive Model Constants," Journal of Applied Physics, Vol. 64, No. 8, pp. 3901-3910, 1988.

3. G. R. Johnson and W. H. Cook, "Fracture Characteristics of Three Metals Subjected to Various Strains, Strain Rates, Temperatures and Pressures," Engineering Fracture Mechanics, Vol. 21, No. 1, pp. 31-48, 1985.

4. Zerilli, F. J. and R. W. Armstrong, "Dislocation-Mechanics-based Constitutive relations for Material Dynamics Calculations," Journal of Applied Physics, Vol. 61, No. 5, pp. 1816$1825,1987$.

5. Zerilli, F. J. and R. W. Armstrong, "Description of Tantalum Deformation Behavior by Dislocation Mechanics Based Constitutive Equations," Journal of Applied Physics, Vol. 68 No. 4, pp. 1580-1591, 1990.

6. Zerilli, F. J. and R. W. Armstrong, "The Effect of Dislocation Drag on the Stress-Strain Behavior of FCC Metals," Acta Metallurgica et Materialia, Vol. 40, No. 8, pp. 1803-1808, 1992

7. Steinberg, D. J., S. G. Cochran, and M. W. Guinan, "A Constitutive Model for Metals Applicable at High-Strain Rate," Lawrence Livermore National Laboratory, UCRL-80465, Revision 2, 1979.

8. Follansbee, P. S. and U. F. Kocks, "A Constitutive Description of the Deformation of Copper Based on the use of the Mechanical Threshold Stress as an Internal State Variable." Acta Metallurgica, Vol. 36, pp. 81-93, 1988.

9. Johnson, G. R., J. M. Hoegfeldt, U. S. Lindholm, and A. Nagy, "Response of Various Metals to Large Torsional Strains over a Large Range of Strain Rates - Part 2: Less Ductile Metals," Journal of Engineering Materials and Technology, Transactions of the ASME. Vol 105, pp. 48-5, 1983.

10. Conrad, H., M. Doner, and B. de Meester, "Deformation and Fracture," in Titanium Science and Technology, R. I. Jaffee and H. M. Burte, Eds., Plenum Press, New York, pp. 969-1005, 1973.

11. Boyer, R., G. Welsch, and E. W. Collings, Materials Properties Handbook: Titanium Alloys, ASM International, Materials Park, OH, 1994.

12. P. W. United Technologies, "Quarterly Progress Report," FR24864-4, Subcontract B340842, 1998.

13. Wulf, G. L., "High Strain Rate Compression of Titanium and Some Titanium Alloys," International Journal of Mechanical Sciences, Vol. 21, 713 - 718, 1979.

14. Follansbee ,P. S. and I. G.T. Gray, "An Analysis of the Low Temperature, Low and High Strain-Rate Deformation of Ti-6Al-4V," Metallurgical Transactions, Vol. 20A, pp. 863 874, 1989.

15. Meyer, L. W., "Strength and Ductility of a Titanium-Alloy Ti-6Al-4V in Tensile and Compressive Loading Under Low, Medium and High Rates of Strain," in Titanium Science and Technology, G. Lutjering, U. Zwicker, and W. Bunk, Eds.: Deutsche Gessellschaft fur Metallkunde, pp. 1851 - 1858, 1984. 
16. Lee, W. S. and C. F. Lin, "Adiabatic Shear Fracture of Titanium Alloy Subjected to High Strain and High Temperature Loadings," Journal de Physique IV, C3, pp. 855-860, 1997.

17. Johnson, G. R., "Strength and Fracture Characteristics of a Titanium Alloy (.06Al, .04V) Subjected to Various Strains, Strain Rates, Temperatures and Pressures," Naval Surface Weapons Center NSWC TR 86-144, 1985.

18. Johnson, G. R. and T. J. Holmquist, "Test Data and Computational Strength and Fracture Model Constants for 23 Materials Subjected to Large Strains, High Strain Rates, and High Temperatures," Los Alamos National Laboratory, LA-11463-MS, 1989.

19. Meyers, M. A., Dynamic Behavior of Materials, John Wiley \& Sons, Inc., New York, 1994.

20. Follansbee, P. S., "High-Strain-Rate Deformation of FCC Metals and Alloys," in Metallurgical Applications of Shock-Wave and High-Strain-Rate Phenomena, L. E. Murr, K. P. Staudhammer, and M. A. Meyers, Eds, Marcel Dekker, Inc., New York, pp. 451 479, 1986.

21. Frost, H. J. and M. F. Ashby, Deformation Mechanism Maps, Pergamon Press, Oxford 1982.

22. Lowden, M. A. W. and W. B. Hutchinson, "Texture Strengthening and Strength

Differential in Titanium-6Al-4V," Metallurgical Transactions, Vol. 6A, pp. 441-448, 1975.

23. Chait, R., "The Strength Differential of Steel and Ti Alloys as Influenced by Test Temperature and Microstructure," Scripta Metallurgica, Vol. 7, pp. 351-354, 1973.

24. O'Donnell, R. G. and R. L. Woodward, "Instability During High Strain Rate Compression of 2024-T351 Aluminum," Journal of Materials Science, Vol. 23, pp. 3578-3587, 1988.

25. Lindholm, U. S. and G. R. Johnson, "Strain-Rate Effects in Metals at Large Shear Strains," in Material Behavior under High Stress and Ultrahigh Loading Rates, 29th Sagamore Army Materials Research Conference Proceedings, Vol. 29, J. Mescall and V. Weiss, Eds, Plenum Press, New York, pp. 61-79, 1982.

26. Brown, W. F. and H. Mindlin, "Aerospace Structural Metals Handbook, Volume 3," CINDAS/USAF CRDA Handbook Operation, pp. 1-17, 1997.

27. ASM International, Source Book on Industrial Alloy and Engineering Data, $\Lambda \mathrm{SM}$ International, Metals Park, OH, 1978.

28. Davis, J. R. et al., ASM Handbook, Volume 2, Properties and Selection: Nonferrous Alloys and Special-Purpose Materials, ASM International, Metals Park, OH, 1990.

29. Air Force Materials Laboratory, Titanium Alloys Handbook: Metals and Ceramics Information Center, 1972.

30. Brown, W. F., H. Mindlin, and C. Y. Ho, “Aerospace Structural Metals Handbook, Volume 4," CINDAS/USAF CRDA Handbook Operation, 1997. 
31. ASM International, "Properties and Selection: Nonferrous Alloys and Special-Purpose Materials," in ASM Handbook, Vol. 2, Materials Park, Ohio: ASM International, p. 638, 1990 ,

32. Lesuer ,D. R., G. Kay, and M. LeBlanc, "Modeling Large Strain, High Rate Deformation in Metals," in Engineering Research, Development and Technology, Lawrence Livermore National Laboratory, UCRL-53868-98, 1999.

\section{APPENDIX}

A. Procedures for Obtaining Parameters for Johnson-Cook Material Model

The parameters in the JC material model are sensitive to the computational algorithm used to calculate the parameters. In this section, the procedures used to obtain the constants for Equation (1) are described. The procedures are illustrated for data analysis of the Ti-6Al-4V alloy. For this study, the response at high strain rate was emphasized. At $25^{\circ} \mathrm{C}$ and constant strain rate, Equation (1) can be written as

$$
\sigma=\left[\mathrm{A}+\mathrm{B \varepsilon ^{n }}\right] \mathrm{C}^{*}
$$

where $\mathrm{C}^{*}$ is a constant. An average stress-strain curve at $\dot{\varepsilon}=5000 \mathrm{~s}^{-1}$ was constructed from the LLNL tension and compression data. The stress at zero plastic strain ( $\mathrm{AC}^{*}$ ) was obtained from this data and found to be $1230 \mathrm{MPa}$. The quantity $\sigma-1230$ was calculated and plotted versus plastic strain on a $\log -\log$ plot as shown in Fig. A1. The quantities $\mathrm{BC}^{*}$ and $\mathrm{n}$ were obtained from a least squares fit of the data to a power law equation as $B C^{*}=1220$ and $n=.93$. The resulting equation is shown in Figure A1. The agreement between the data (open circles) and the predictions (solid line) is excellent, illustrating that the strain hardening response of the alloy can be represented well by a power law equation.

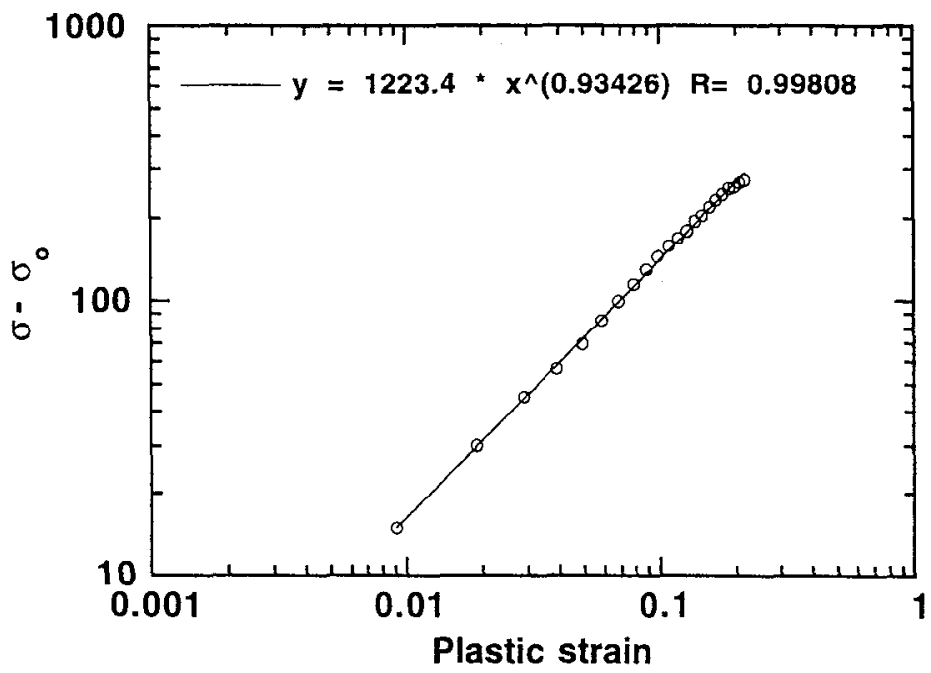

FIGURE A1. $\sigma-\sigma_{0}$ VERSUS PLASTIC STRAIN FOR THE Ti-6Al-4V ALLOY AT A STRAIN RATE OF $5000 \mathrm{~s}^{-1}$. $\sigma_{0}$ IS THE STRESS AT 0 PLASTICSTRAIN. 
The parameter $\mathrm{C}$ was obtained from $\sigma-\dot{\boldsymbol{\varepsilon}}$ data. At $25^{\circ} \mathrm{C}$ and constant strain, Equation (1) can be written as

$$
\frac{\sigma}{\sigma_{\mathrm{a}}}-1=\mathrm{C} \ln \dot{\varepsilon}
$$

where $\sigma_{\mathrm{a}}$ is the stress at $\dot{\varepsilon}=1 \mathrm{~s}^{-1}$. From the data in Fig. $11(\varepsilon=.04), \sigma_{\mathrm{a}}=1146 \mathrm{MPa}$ and $\sigma_{\mathrm{a}}-1$ is plotted versus $\dot{\boldsymbol{\varepsilon}}$ on a semi-log plot (Fig. A2). A least squares fit to the data shows that $\mathrm{C}=.014$. The parameters $A$ and $B$ can now be calculated as $A=862 \mathrm{MPa}$ and $B=331 \mathrm{MPa}$.

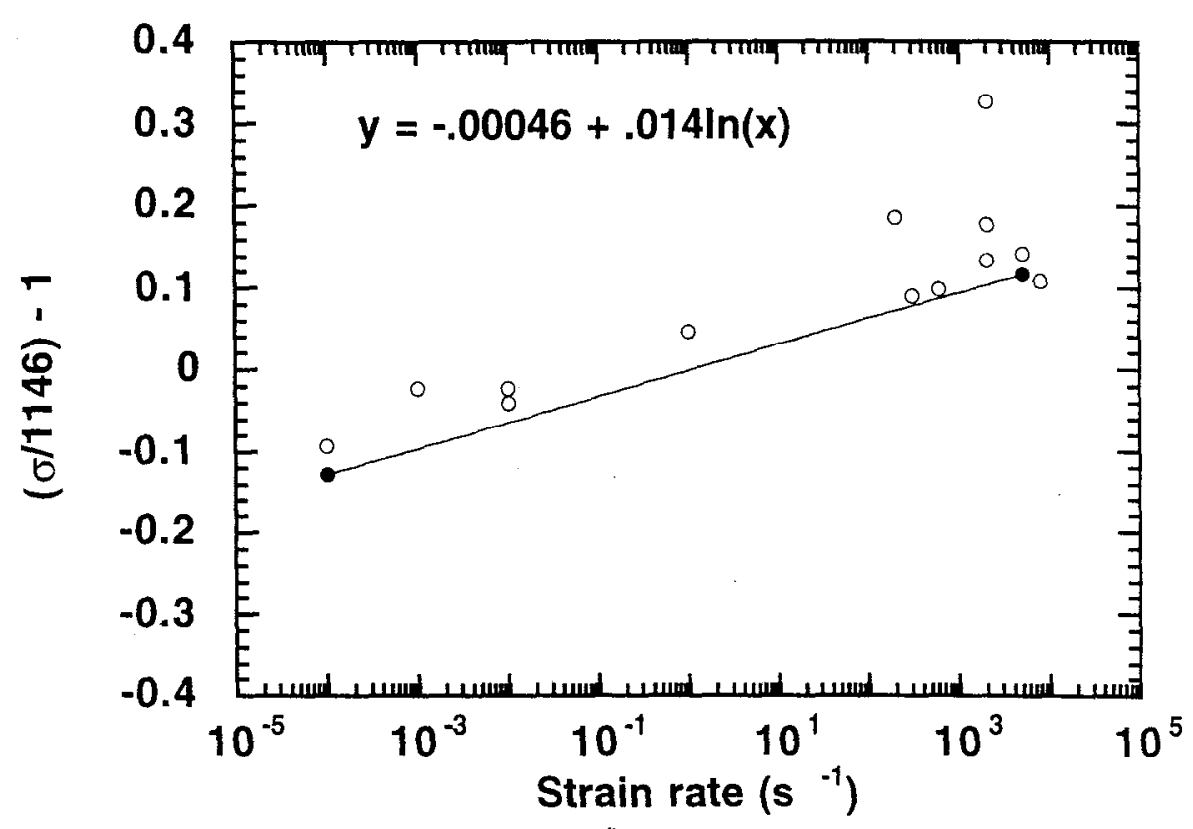

FIGURE A2. $\sigma / \sigma_{1}$ VERSUS STRAIN RATE FOR THE Ti-6Al-4V ALLOY. $\sigma_{1}$ IS THE STRESS AT A STRAIN RATE OF $1 \mathrm{~s}^{-1}$.

The parameter $m$ was determined from the stress - temperature response of the alloy. Data compiled from the literature is presented in Fig. A3 and shows the stress - temperature response at low and high strain rates and, for the high rate data, 3 different strains. At constant strain and strain rate, Equation (1) can be written as

$$
\frac{\sigma}{\sigma_{b}}=1-T^{* m}
$$

where $\sigma_{b}$ is the stress at $25^{\circ} \mathrm{C}$. The data at $2500 \mathrm{~s}^{-1}$ and $\varepsilon=.04$ were used and $\sigma_{b}$ was found to be $1350 \mathrm{MPa}$. The data was plotted as $\sigma / 1350$ versus $\mathrm{T}^{*}$, and the value of $\mathrm{m}$ providing the best fit to Equation A3 was established as shown in Fig. A4. 


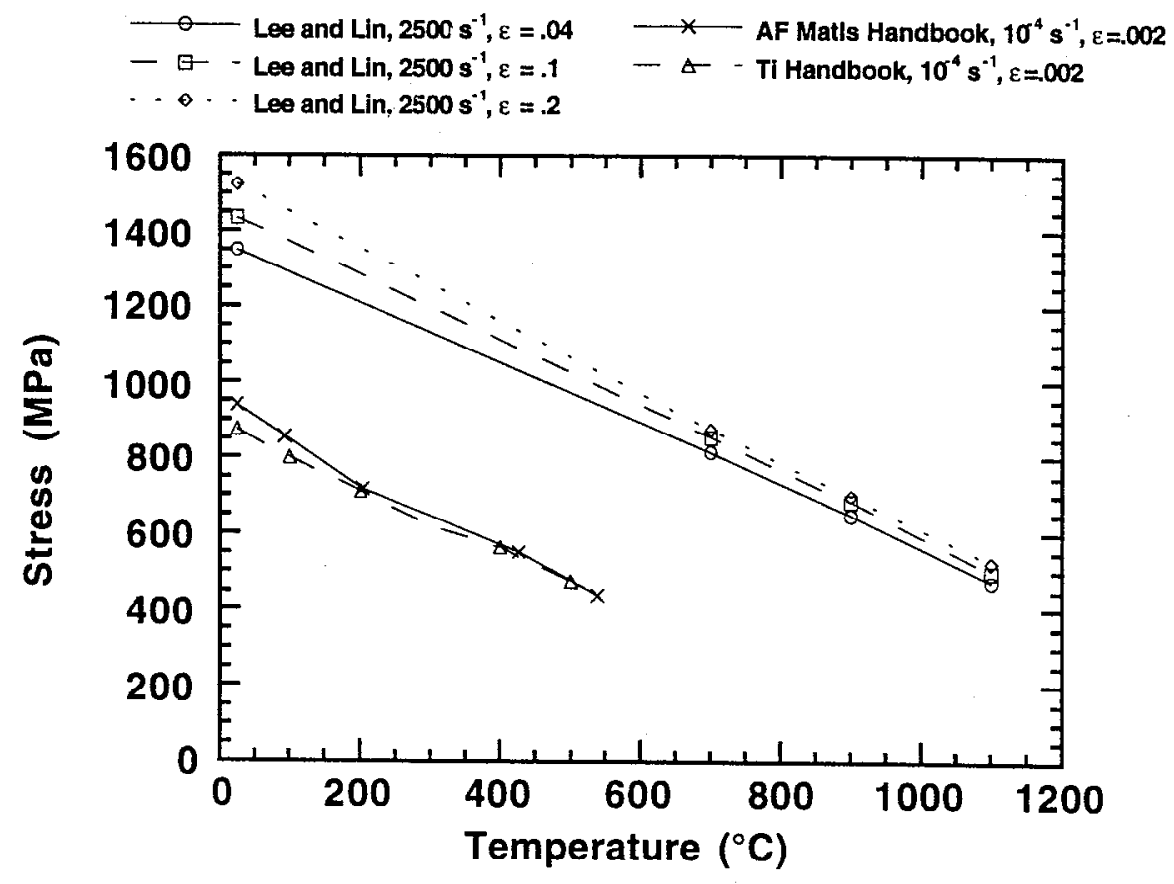

FIGURE A3. STRESS VERSUS TEMPERATURE FOR THE Ti-6Al-4V ALLOY AT BOTH HIGH STRAIN RATES AND LOW STRAIN RATES.

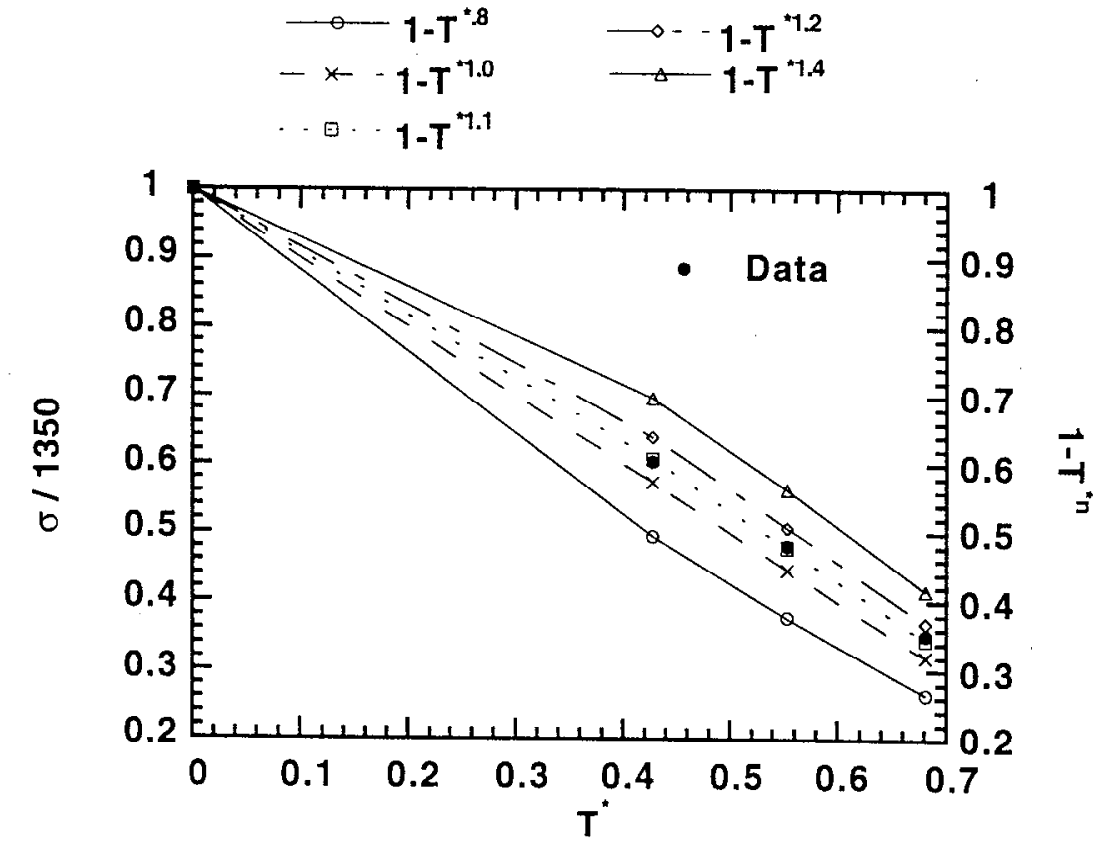

FIGURE A4. $\sigma / \sigma_{\mathrm{a}}$ VERSUS T* FOR THE Ti-6Al-4V ALLOY. $\sigma_{\mathrm{a}}$ IS THE STRESS AT $298 \mathrm{~K}$ AND T* IS DEFINED IN THE TEXT. 